Article

\title{
Optical Properties of Biomass Burning Aerosols: Comparison of Experimental Measurements and T-Matrix Calculations
}

\author{
Samin Poudel ${ }^{1}$, Marc N. Fiddler ${ }^{1}$, Damon Smith ${ }^{2}$, K. M. Flurchick ${ }^{1,3}$ and Solomon Bililign ${ }^{1,4, *}$ \\ 1 Department of Physics, North Carolina A\&T State University, Greensboro, NC 27401, USA; \\ spoudel@aggies.ncat.edu (S.P.); marc.fiddler@gmail.com (M.N.F.); kmflurch@ncat.edu (K.M.F.) \\ 2 Department of Energy and Environmental Systems, North Carolina A\&T State University, \\ Greensboro, NC 27401, USA; dmsmit13@aggies.ncat.edu \\ 3 Department of Computational Science and Engineering, North Carolina A\&T State University, \\ Greensboro, NC 27401, USA \\ 4 NOAA-ISET Center, North Carolina A\&T State University, Greensboro, NC 27401, USA \\ * Correspondence: bililignsol@gmail.com; Tel.: +1-336-285-2328
}

Received: 4 September 2017; Accepted: 16 November 2017; Published: 21 November 2017

\begin{abstract}
The refractive index (RI) is an important parameter in describing the radiative impacts of aerosols. It is important to constrain the RI of aerosol components, since there is still significant uncertainty regarding the RI of biomass burning aerosols. Experimentally measured extinction cross-sections, scattering cross-sections, and single scattering albedos for white pine biomass burning (BB) aerosols under two different burning and sampling conditions were modeled using T-matrix theory. The refractive indices were extracted from these calculations. Experimental measurements were conducted using a cavity ring-down spectrometer to measure the extinction, and a nephelometer to measure the scattering of size-selected aerosols. BB aerosols were obtained by burning white pine using (1) an open fire in a burn drum, where the aerosols were collected in distilled water using an impinger, and then re-aerosolized after several days, and (2) a tube furnace to directly introduce the BB aerosols into an indoor smog chamber, where BB aerosols were then sampled directly. In both cases, filter samples were also collected, and electron microscopy images were used to obtain the morphology and size information used in the T-matrix calculations. The effective radius of the particles collected on filter media from the open fire was approximately $245 \mathrm{~nm}$, whereas it was approximately $76 \mathrm{~nm}$ for particles from the tube furnace burns. For samples collected in distilled water, the real part of the RI increased with increasing particle size, and the imaginary part decreased. The imaginary part of the RI was also significantly larger than the reported values for fresh BB aerosol samples. For the particles generated in the tube furnace, the real part of the RI decreased with particle size, and the imaginary part was much smaller and nearly constant. The RI is sensitive to particle size and sampling method, but there was no wavelength dependence over the range considered (500-680 $\mathrm{nm}$ ). Our values for the RI of fresh (white pine) biomass burning aerosols ranged from $1.33+\mathrm{i} 0.008$ to $1.74+\mathrm{i} 0.008$ for $200-\mathrm{nm}, 300-\mathrm{nm}$, and 400-nm diameter particles. These are within the range of RI values in the most recent study conducted during the Fire Laboratory at Missoula Experiments (FLAME I and II), which were 1.55 to 1.80 for the real part, and 0.01-0.50 for the imaginary part, for fresh BB aerosols with diameters of $200-570 \mathrm{~nm}$. There is no clear trend on the dependence of the RI values on particle size. The RI values derived from measurements of aerosols produced from the combustion of hydrocarbons and diesel cannot be used for BB aerosols.
\end{abstract}

Keywords: aerosol optical properties; biomass burning aerosols; T-matrix; refractive index 


\section{Introduction}

With an estimated total climate forcing of $+1.1 \mathrm{~W} \cdot \mathrm{m}^{-2}$, black carbon $(\mathrm{BC})$ is the second most important human emission in terms of its climate forcing in the present-day atmosphere, second to $\mathrm{CO}_{2}$ [1]. $\mathrm{BC}$ is produced during the combustion of carbon-based fuels when oxygen is insufficient for complete combustion, which occurs during biomass burning (BB) [1,2]. In biomass burning, flaming combustion is characterized by the production of $\mathrm{BC}$, while smoldering combustion is dominated by the production of organic carbon (OC), including brown carbon $(\mathrm{BrC})$. Soot or $\mathrm{BC}$ is a term used interchangeably by the Intergovernmental Panel on Climate Change (IPCC) and others $[1,3,4]$. The uncertainty in the measurements of aerosol optical properties has made it difficult to quantify the global impact of aerosols on Earth's climate, and limits our ability to predict future climate changes $[1,5]$.

The scattering and absorption of light by small particles has long been an important research subject across several disciplines, including atmospheric and oceanic science, astrophysics, bioscience, and medical science. The properties of scattering and absorption are determined by particle volume, shape, and refractive index (RI). However, there is a growing need for improved knowledge of scattering and absorption properties of $\mathrm{BC}$ and $\mathrm{BC}$-containing aerosols for remote sensing applications and atmospheric radiation budget computations [5-16].

Owing to their very complex morphology, modeling the scattering and absorption properties of biomass aerosols is nontrivial, and several approximations have been employed with limited success. Electron microscope images of soot particles show that they are emitted as complex chain structures [17], which tend to collapse upon humidification and/or as the particles age [17-20], thereby changing their optical properties. The extreme complexity of these morphologies can limit our ability to compute the scattering and absorption properties of realistic BC and BC-containing aerosol with requisite accuracy. Yet, the rapid growth of computational power, coupled with the availability of efficient numerically-exact computer solvers of the Maxwell equations [21-24], has led to advances in computational techniques. The scattering and absorption of light by fractal aggregates with soot-like refractive indices have been performed using various approximate and numerical techniques [25-29]. The T-matrix method has been increasingly applied to the computation of electromagnetic scattering by multi-sphere clusters [10,23,30-37]. Recently, the Multiple Sphere T-matrix model $[33,38,39]$ has been used to calculate the radiative properties of these aerosols. In this work, we employ T-matrix methods to calculate the scattering and absorption properties of fresh fractal BB aerosol aggregates, and extract their refractive indices.

The collection of $\mathrm{BB}$ aerosols on filters or impactor plates allowed us to study the morphology of the BB particles. TEM images of individual carbonaceous BB aerosols show that they exist in the form of clusters of small, nearly spherical monomers (spherules), and the traditional Lorenz-Mie theory [23] may not be applicable. The statistical scaling law may be more appropriate $[40,41]$.

$$
N_{S}=k_{o}\left(\frac{R_{g}}{a}\right)^{D_{f}}
$$

Equation (1) is used to represent the overall morphology of a dry BB aerosol as a fractal cluster [40,41]. In Equation (1), $a$ is the monomer mean radius, $k_{0}$ is the fractal pre-factor, $D_{f}$ is the fractal dimension, $N_{S}$ is the number of monomers in the cluster, and $R_{g}$, called the radius of gyration, is a measure of the overall cluster radius. The radius of gyration is represented as:

$$
R_{g}^{2}=\frac{1}{\sum R_{i}^{3}} \sum R_{i}^{3}\left(a_{i-C M}^{2}+R_{g, i}^{2}\right)
$$

where $R_{i}$ is the radius of the $i$ th primary particle, $a_{i-C M}$ is the separation distance of the $i$ th monomer from the center of the mass of the particle; and $R_{g, i}$ is the radius of the $i$ th primary particle $\left(R_{g, i}^{2}=0.6 R_{i}^{2}\right)[42]$. The fractal dimension $D_{f}$ is important for the quantitative characterization of 
the aggregate's morphology. The other important structural coefficient, $k_{0}$ is also related to the state of compactness of a fractal particle. For a fixed $D_{f}$, the packing density tends to be smaller as $k_{0}$ decreases [43]. Generally, BB aerosols formed in wildfires and emitted as aggregates have a fractal dimension $D_{f}$ of $\sim 1.8$, but the presence of $\mathrm{BB}$ superaggregates (SAs) in the outflow from a major wildfire in India had a $D_{f}$ of $\sim 2.6$ [44].

The refractive index is an important parameter in describing the radiative impacts of aerosols. The reported refractive indices for black carbon particles are quite diverse, and possibly depend on the fuel type, experimental approach and method of sample preparation/generation. Bond and Bergstrom [2] recommended the wavelength-independent values of the refractive index in the visible wavelength at $0.55 \mu \mathrm{m}$, ranging from $1.75+\mathrm{i} 0.63$ to $1.95+\mathrm{i} 0.79$ for strongly-absorbing soot particles. However, these values are based on soot produced by burning kerosene, propane, toluene, a candle flame, and diesel fuel. A wavelength-dependent refractive index [45] based on Equations (3) and (4) was also found [45]:

$$
\begin{aligned}
& n=1.811+0.1263 \ln \lambda+0.027(\ln \lambda)^{2}+0.0417(\ln \lambda)^{3} \\
& k=0.5821+0.1213 \ln \lambda+0.02309(\ln \lambda)^{2}-0.01(\ln \lambda)^{3}
\end{aligned}
$$

which is valid for wavelengths from 0.4 to 30 microns, and for soot produced from a premixed propane-oxygen flame. It has also been shown that the refractive index of brown carbon has some degree of wavelength dependence, contrary to widely held assumptions of wavelength independence [46].

One common method of retrieving the refractive index is based on the work by Raziq et al. [47]. The values of efficiencies $Q_{a b s}, Q_{\text {scatt}}$, and $Q_{\text {ext }}$ are calculated using the Mie code for values of the real and imaginary parts of the index of refraction, and using experimental values of extinction and scattering cross-sections, a best fit is found by minimizing the error between the calculated and measured values [48]. However, this assumes the particles are pure spheres, which is not the case for real BB aerosols. Other researchers used a combination of the Rayleigh-Debye Gans (RDG) theory, which treats particles as fractal-like aggregates of small spheres, and Mie theory, to study the optical properties of combustion particles from propane. However, this method produced single scattering albedo (SSA) values that were underestimated by $56 \%$ when compared with the experimental results [46]. The imaginary part of the refractive index also showed a wavelength dependence, which decreased with increasing wavelength. BB aerosols were generally believed to be composed of carbon, with organic species accounting for the largest mass fraction, in most cases. During the Fire Laboratory at Missoula Experiments (FLAME), the real and imaginary refractive indices had ranges of 1.55-1.80 and $0.01-0.50$, respectively, which were strongly dependent on the chemical composition and density of the aerosols [49].

In this work, we applied the T-matrix method to extract the refractive index of BB aerosols from experimentally measured SSA, scattering, and extinction cross-section values obtained using a cavity ring-down spectrometer and a nephelometer. BB aerosols were produced by burning pine and collecting aerosols in two different ways using: (1) an open fire in a burn drum to burn pine, and collect $\mathrm{BB}$ aerosols in distilled water using an impinger, which was re-aerosolized after several days, and (2) a tube furnace in the lab to burn pine, after which the resulting BB aerosols were directly introduced into an indoor smog chamber, and BB aerosols were sampled directly from the chamber. In both cases, filter samples were also collected from both types of burning, and electron microscopy images were used to obtain morphology and size information to conduct T-matrix calculations.

\section{Experimental Approach}

Filter samples were collected and imaged to determine the shape and size of BB aerosols produced by burning white pine. White pine wood was air dried for several months before the burn, and was burned at an outdoor location, as well as inside the laboratory in a tube furnace. During the open fire 
burn, freshly emitted BB aerosol samples generated in a burn drum were collected using previously described methods [50]. Briefly, wood was burned in a burn drum with adjustable vents and a lid with a chimney pipe. Smoke exiting through the chimney was sampled with a copper tube with an outer diameter of $0.5 \mathrm{in}$, which served as a heat exchanger. A Teflon tube was connected to the copper tube, and particles were sampled by a cascade impactor, a liquid impinger, and a scanning mobility particle sizer (SMPS). Sampling time was $<30 \mathrm{~min}$ at a flow rate of $12.5 \mathrm{~L} / \mathrm{min}$, and $30 \mathrm{~mL}$ of distilled water was used in the impinger. Residence time from combustion to sampling was on the order of tens of seconds. Flaming and smoldering burning stages were differentiated visually. For laboratory samples, BB aerosols were generated by combusting wood samples in a tube furnace. The furnace (Carbolite Gero, HST120300-120SN, Carbolite Gero, Hope, UK) holds a 86-mm OD quartz working tube, and has a heated region of $300 \mathrm{~mm}$. Stainless steel mounts and insulation plugs on either end enable the introduction and sampling of gases. Air was introduced to the furnace at $10 \mathrm{sL} / \mathrm{min}$ from a calibrated mass flow controller (MFC, Sierra Instruments, Monterey, CA, USA), and was supplied by house compressed air that passed through a zero air generator (Aadco Instruments, 747-30, Cleves, OH, USA). The furnace was preheated to $500{ }^{\circ} \mathrm{C}$, and blank measurements were taken at each particle size of whatever small concentrations of particles that were generated this way. Wood samples (white pine) were weighed to $\sim 100 \mathrm{mg}$ and placed in a quartz combustion boat (AdValue Technology, FQ-BT-03, Tucson, AZ, USA), which was in turn placed at the center of the furnace. The flaming stage was very short lived, and the smoldering stage was observed in the tube furnace. The smoke and gases produced from combustion were sent directly to the chamber via a heated $\left(200^{\circ} \mathrm{C}\right), 1 / 4$ inch stainless steel transfer tube. Afterwards, the gases underwent cooling and dilution in a similar fashion to natural processes, as opposed to stepwise dilution and cooling, which introduces a hysteresis in the condensation of semi-volatile species. There was no chemical analysis done to observe the organics coating on the aerosols, but we believe that for the impinger samples, most of the organics dissolved in the water and left little or no coating when the samples were re-aerosolized. It was shown that most of the BB aerosol material (on average about $50 \%$ ) seemed to be highly refractory organic material soluble in water [51]. For aerosols produced in the tube furnace and sampled from the chamber, studies have shown [52] that the chamber walls become a sink for condensable vapors, such as the organic compounds on the particles. The environmental chamber has a volume of $9.01 \mathrm{~m}^{3}$ and is lined by FEP Teflon. While not used in this work, its two sides have two banks of ultraviolet lights (Sylvania, F30T8/350BL/ECO, 36", Wilmington, MA, USA) with a total of 64 lamps.

Pressure (Omega Instruments Part \# PX309-015AI, Norwalk, CT, USA), relative humidity, and temperature (Traceable Products, model4085, Webster, TX, USA) were also monitored. CO and $\mathrm{CO}_{2}$ were measured with a non-dispersive IR spectrometer. Other available chemical measurements, such as $\mathrm{O}_{3}, \mathrm{NO}_{x}$, and organic compounds, were not directly used here, and will be discussed in forthcoming work.

The details of the Cavity Ring Down Spectroscopy (CRDS)/nephelometry system was thoroughly described in our recent paper [50]. Briefly, for impinger samples, a constant output nebulizer (TSI model 3076 , Shoreview, MN, USA) in circulation mode was used in generating aerosols from an aqueous solution of suspended particles. This was followed by a diffusion dryer (TSI model 3062, Shoreview, MN, USA). Flow from either the dryer or the Teflon environmental chamber entered a 710- $\mu \mathrm{m}$ impactor inlet (3.8 $\mu \mathrm{m}$ diameter cut point) neutralizer (TSI model 3081, Shoreview, MN, USA), and a long differential mobility analyzer (DMA) (TSI model 3080, Shoreview, MN, USA) where particles can be size selected. A coupled differential mobility analyzer (DMA) and condensation particle counter (CPC) (TSI model 3788, Shoreview, MN, USA) (i.e., scanning mobility particle sizer (SMPS)) was used to determine the size distributions. Particles with mobility diameters between 200-500 nm were selected at $100 \mathrm{~nm}$ intervals with the DMA. We have determined the size distributions, specifically, the standard deviations while sampling from the chamber (sheath flow of $2.8 \mathrm{~L} / \mathrm{m}$ ) and impinger (sheath flow of $3.0 \mathrm{~L} / \mathrm{m}$ ), and showed no overlap. A pump within the CPC produces flow through the entire system $(0.58 \mathrm{sL} / \mathrm{min})$, and the DMA sheath flow was $6.0 \mathrm{~L} / \mathrm{min}$ in single blower mode. 
It has been shown that the presence of large, multiply charged particles passed by the DMA can artificially increase measured cross-sections, even if their number density is relatively small. We conducted a very detailed calibration and error analysis of the system used for performing optical properties measurements of soot [53]. While this effect was recognized in our previous work, the contribution of larger particles was not quantified. For the smallest particles here and elsewhere, the observed fluctuations in absolute and relative extinction cross-sections $\left(\sigma_{\text {ext }}\right)$ were much greater for small particles than for larger particles, and measured $\sigma_{\mathrm{ext}}$ are consistently and appreciably larger than theoretical predictions. We had recommended that the extinction-minus-scattering method utilizing CRDS and nephelometery be limited to particles with diameters $\geq 200 \mathrm{~nm}$.

In our most recent work, we showed that SSA can be altered by less than 0.018 due to the effects of multiple charging, and alterations are typically less than this [50]. This analysis has been performed for $200 \mathrm{~nm}$ particles; since there are direct measurements of SSA for $200 \mathrm{~nm}$ particles and $400 \mathrm{~nm}$ particles (i.e., those whose mobility in the +2 charge state would match the +1 charged, 200-nm particles). This was done by applying an in-software algorithm to the SMPS spectrum to derive the true size distribution. The fraction of $200 \mathrm{~nm}$ particles (relative to the sum of $200 \mathrm{~nm}$ and $400 \mathrm{~nm}$ particles) was found for each run, and averaged. The contribution of each size to the observed SSA (or cross-section) was found by assuming that the contribution of each was additive, and that $400 \mathrm{~nm}$ particles exhibited their "true" SSA or cross-section (i.e., they were not influenced by even larger particles). Each term is the product of the relative concentration, the charge probability $(+1$ for $200 \mathrm{~nm}$ particles and +2 for $400 \mathrm{~nm}$ particles), and their true SSA. This was rearranged to find the true SSA or cross-section for singly charged $200 \mathrm{~nm}$ particles. We have found that particles of this mobility are composed of $99.6 \%$ of +1 charged, $200 \mathrm{~nm}$ particles, with +2 charged, $400 \mathrm{~nm}$ particles making up the balance $(+3$ charged, $600 \mathrm{~nm}$ particles were not considered, since their SSA was unknown). The SSA was unaffected by this consideration, changing by less than $\pm 0.07 \%$.

However, extinction was somewhat more affected, as may be expected by the removal of larger, more highly charged particles. The extinction cross-section dropped by $1.3-2.7 \%$ (an average of $1.8 \%$ ), which is (3.46-5.99) $\times 10^{-16} \mathrm{~m}^{2} /$ particle. No correction due to multiple charges was made in the data reported here. Larger particles cannot be as thoroughly assessed, since their SSA and extinction cross-sections were not measured, but the effect of multiple charging is expected to be less, given the smaller number concentrations of larger particles.

Size-selected aerosols then entered a ring-down cavity, where the aerosol light extinction was measured over a range of wavelengths between 500-660 $\mathrm{nm}$. The laser light was provided by an optical parametric oscillator (OPO) (Surelite OPO Continuum, San Jose, CA, USA) laser that was pumped by $355 \mathrm{~nm}$ of a Surelite I-20 Nd:YAG laser (Continuum, San Jose, CA, USA) running at $20 \mathrm{~Hz}$. Spectra were recorded at 2-nm intervals, with 200 shots averaged at each wavelength. Typically, two to three spectra were recorded for each particle size. The entire system was flushed for 15-20 min when the size selection was changed. Scanning mobility particle spectra were recorded before and after each set of experiments. Two sets of mirrors were used in the previous work for samples collected from the open fire, and a single set was used for samples collected from the indoor furnace. The extinction coefficient $\alpha_{\text {ext }}\left(\mathrm{m}^{-1}\right)$ was measured by the CRDS, and the extinction cross-section $\sigma_{\text {ext }}\left(\mathrm{m}^{2} /\right.$ particle) was found using $\alpha_{\text {ext }}$ and the number density of particles $N_{C R D}$ (particles $/ \mathrm{cm}^{3}$ ) in the Cavity Ring Down (CRD) cavity. The average CPC number densities were 822 particles $/ \mathrm{cm}^{3}$ for 200-nm particles, 201 particles $/ \mathrm{cm}^{3}$ for 300-nm particles, and 56 particles $/ \mathrm{cm}^{3}$ for $400-\mathrm{nm}$ particles.

After the CRDS, aerosol light scattering coefficients were measured at $453 \mathrm{~nm}, 554 \mathrm{~nm}$, and $698 \mathrm{~nm}$ using the integrating nephelometer (TSI, model 3563, Shoreview, MN, USA), and particle concentration was measured by the CPC. The absorption cross-section was derived from the difference between the scattering and extinction cross-sections. SSA was found by dividing the scattering cross-section by the extinction cross-section. These calculations and the propagation of their errors were discussed in previous work [53]. Briefly, for extinction, the coefficients were measured several times for a specific size and wavelength. Several factors, including statistical fluctuations in particle counts or number 
densities measured by the CPC, including the error associated with measuring $\mathrm{R}_{\mathrm{L}}$ (distance occupied by the sample relative to mirror-to-mirror distance), and the error associated with the blank cavity ring down time was used to calculate the average cross-section and average errors (one standard deviation). A similar process was used for scattering cross-sections by including the correction factor and associated error. Specifically, a broadband correction factor was used to reconcile scattering and extinction for purely scattering spheres, and the empirical absorption Ångstrom exponent-based correction of Anderson and Ogren was used to account for the truncation error. The SSA and its error were based on scattering and extinction coefficients, the relative standard deviations of these coefficients, and the relative number of densities in the cavity and nephelometer. At two standard deviations, the CRDS/nephelometer system can safely determine SSA values of $\leq 0.91$, with $\leq 0.96$ achievable on average [53]. Figure 1 shows the schematics of the experimental process.

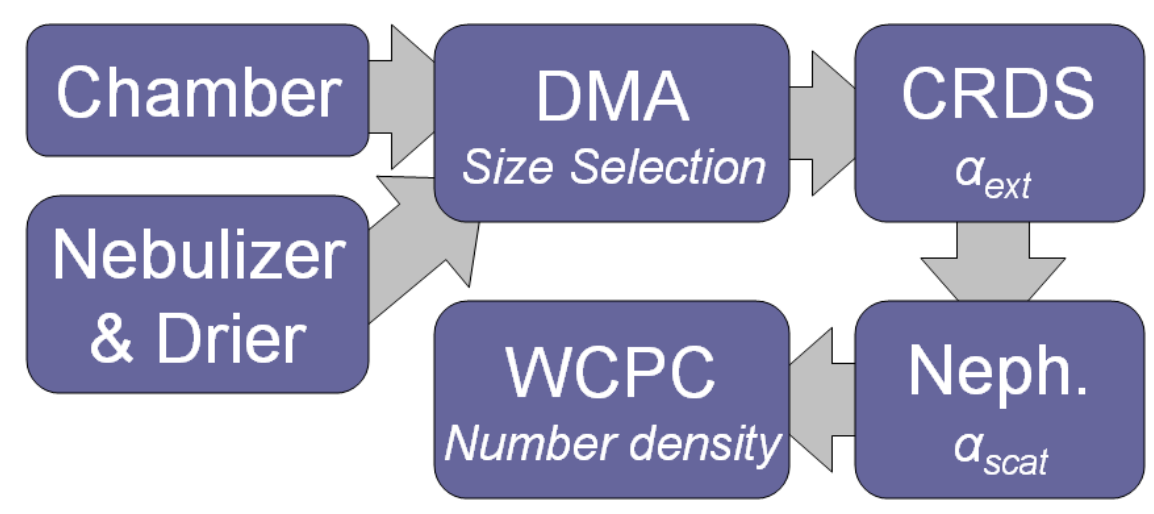

Figure 1. Schematics of the experimental set-up.

Particles were sampled with 47-mm Teflon filters (Tisch Environmental, SF18040, 2- $\mu$ m pore diameter, Cleves, OH, USA). Samples were drawn at $6 \mathrm{~L} / \mathrm{min}$ for $15 \mathrm{~min}$. Filters were cut to size, mounted on sample holders, then gold coated using standard methods. Images were taken using a scanning electron microscope (SEM) (Auriga, ZESIS, Oberkochen, Germany) at the Joint School of Nanoscience and Nanoengineering (JSNN). The secondary electron secondary ion (SESI) and InLens detectors were used for taking images. Distinct images of polydisperse spheroidal BB aerosols were captured with appropriate magnification and saved in tiff format. For each filter sample, five to ten images were captured.

\section{Theoretical Approach}

With the continuous improvements and successful applications, the T-matrix method formulated by Watermann in 1965 [54] has already become one of the most reliable theoretical techniques to treat electromagnetic as well as acoustic and elastodynamic scattering by single and aggregated scattering particles, multiple scattering in discrete random media, and scattering by gratings and periodically rough surfaces [23]. The derivations and formalism outlined in this paper are based on the work by Mischenko, Travis, and Mackowski [35].

For a plane, electromagnetic wave incidents in the direction of propagation of unit vector $\mathbf{n}$, or equivalently, a couple $(\vartheta, \varphi)$, is expressed as:

$$
\mathbf{E}^{\mathrm{inc}}(\mathbf{R})=\mathbf{E}^{\mathrm{inc}} \exp \left(i k \mathbf{n}_{\mathrm{inc}} \mathbf{R}\right)=\left(E_{\vartheta}^{i n c} \vartheta_{\mathrm{inc}}+E_{\varphi}^{i n c} \varphi_{\mathrm{inc}}\right) \exp \left(i k \mathbf{n}_{\mathbf{i n c}} \mathbf{R}\right)
$$

where $\mathbf{R}$ is the radius vector with its origin at the origin of the coordinates system, $k=\frac{2 \pi}{\lambda}$ is the free space wave number for free space wavelength $\lambda, \vartheta_{\text {inc }}$ and $\varphi_{\text {inc }}$ are the unit vectors in the $\vartheta$-direction and $\varphi$-direction, respectively, and $\mathbf{n}_{\mathbf{i n c}}=\left(\vartheta_{\text {inc }} \times \varphi_{\text {inc }}\right)$. In all of the equations for electromagnetic 


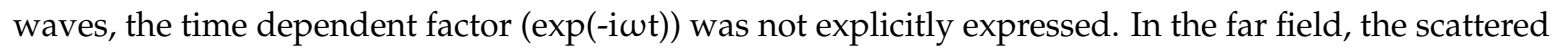
wave becomes:

$$
\mathbf{E}^{\mathrm{sca}}(\mathbf{R})=E_{\vartheta}^{s c a}\left(R, \mathbf{n}_{\text {sca }}\right) \vartheta_{\text {sca }}+E_{\varphi}^{s c a}\left(R, \mathbf{n}_{\text {sca }}\right) \varphi_{\text {sca }}
$$

where $\mathbf{n}_{\mathbf{s c a}}=\mathbf{R} / R$, and is valid for $\mathrm{k} R>>1$

$$
\mathbf{R} \cdot \mathbf{E}^{\mathrm{sca}}(\mathbf{R})=\mathbf{0}
$$

The $\vartheta$ and $\varphi$ components of the incident field can be transformed into the respective components of the scattered field using the amplitude scattering matrix $\mathbf{S}$ [23]:

$$
\left[\begin{array}{c}
E_{\vartheta}^{s c a} \\
E_{\varphi}^{s c a}
\end{array}\right]=\left(\frac{\exp (i k R)}{R}\right) \mathbf{S}\left(\mathbf{n}_{\mathbf{s c a}}, \mathbf{n}_{\mathbf{i n c}}\right)\left[\begin{array}{c}
E_{\vartheta}^{i \vartheta c} \\
E_{\varphi}^{i n c}
\end{array}\right]
$$

$\mathbf{S}$ is a $(2 \times 2)$ amplitude scattering matrix. It linearly transforms the electric vector component of the incident wave into the electric vector component of the scattered wave. As the scattering amplitude matrix is the primary term that defines the scattering law, if it is known for a particle, then other scattering properties of the particle can also be determined [35].

In the T-matrix approach, the primary step is to express the incident and scattered fields in terms of the vector spherical functions $\mathbf{M}_{m n}$ and $\mathbf{N}_{m n}$ [22]:

$$
\begin{aligned}
& \mathbf{E}^{\mathrm{inc}}(\mathbf{R})=\sum_{n=1}^{\infty} \sum_{m=-n}^{n}\left[a_{m n} \operatorname{Rg} \mathbf{M}_{m n}(k \mathbf{R})+b_{m n} \operatorname{Rg} \mathbf{N}_{m n}(k \mathbf{R})\right] \\
& \mathbf{E}^{\mathrm{sca}}(\mathbf{R})=\sum_{n=1}^{\infty} \sum_{m=-n}^{n}\left[p_{m n} \mathbf{M}_{m n}(k \mathbf{R})+q_{m n} \mathbf{N}_{m n}(k \mathbf{R})\right]
\end{aligned}
$$

where $\mathrm{R}>\mathrm{r}_{0}$, and $\mathrm{r}_{0}$ is the radius of the circumscribing sphere of the scattering particle. $\operatorname{Rg} \mathbf{M}_{m n}$ and $\operatorname{Rg} \mathbf{N}_{m n}$ are obtained by replacing spherical Hankel functions $h_{n}^{(1)}$ with spherical Bessel functions $\mathrm{j}_{n}$ in the equations describing $\mathbf{M}_{m n}$ and $\mathbf{N}_{m n}$ (Equations (7) and (8) of reference [35]). $\operatorname{Rg} \mathbf{M}_{m n}$ and $\operatorname{Rg} \mathbf{N}_{m n}$ are regular at the origin, while the use of the outgoing functions $\mathbf{M}_{m n}$ and $\mathbf{N}_{m n}$ ensures that the scattered field satisfies the radiation condition at infinity.

The relation between the scattered field coefficients $p_{m n}$ and $q_{m n}$ and the incident field coefficients $a_{m n}$ and $b_{m n}$ is linear because of the linearity of Maxwell's equation and the boundary conditions. This is given by the transition matrix $\mathbf{T}$, as follows:

$$
\begin{aligned}
& p_{m n}=\sum_{n^{\prime}=1}^{\infty} \sum_{m^{\prime}=-n^{\prime}}^{n^{\prime}}\left[T_{m n m^{\prime} n^{\prime}}^{11} a_{m^{\prime} n^{\prime}}+T_{m n m^{\prime} n^{\prime}}^{12} b_{m^{\prime} n^{\prime}}\right] \\
& q_{m n}=\sum_{n^{\prime}=1}^{\infty} \sum_{m^{\prime}=-n^{\prime}}^{n^{\prime}}\left[T_{m n m^{\prime} n^{\prime}}^{21} a_{m^{\prime} n^{\prime}}+T_{m n m^{\prime} n^{\prime}}^{22} b_{m^{\prime} n^{\prime}}\right]
\end{aligned}
$$

The above equation is the key for the T-matrix approach. As the expansion coefficients of the incident plane wave are calculated using closed-form analytical expressions [55], one can calculate the scattered field, provided that components of the T-matrix are known.

One of the most important characteristics of the T-matrix approach is that it depends only on the physical and geometrical features such as refractive index, size, shape, and orientation, and does not show any dependence on the incident and scattered fields. The computed T-matrix can also be used for any non-spherical particle in an arbitrary orientation in the analytical computation of the scattering characteristics of randomly oriented particles [55]. The extinction and scattering cross-sections averaged over the uniform orientation distribution of a non-spherical particle can be found using the following relations: 


$$
\begin{aligned}
& C_{e x t}=-\frac{2 \pi}{k^{2}} \operatorname{Re} \sum_{n=1}^{\infty} \sum_{m=-n}^{n}\left[{ }^{1} T_{m n m n}^{11}+{ }^{1} T_{m n m n}^{12}\right] \\
& C_{s c a}=\frac{2 \pi}{k^{2}} \sum_{n=1}^{\infty} \sum_{n^{\prime}=1}^{\infty} \sum_{m=-n}^{n} \sum_{m^{\prime}=-n^{\prime}}^{n^{\prime}} \sum_{i=1}^{2} \sum_{j=1}^{2}\left|1 T_{m n m^{\prime} n^{\prime}}^{i j}\right|^{2}
\end{aligned}
$$

The superscript on the left of $T$ refers to the natural coordinate system of the scatterer, which can be arbitrary for irregularly shaped particles. The values of orientationally averaged extinction and scattering cross-sections are the same for any of the coordinate system used [35].

Absorption cross-section and SSA, which is often represented as $\left(\omega_{0}\right)$, are calculated as:

$$
\begin{aligned}
& C_{a b s}=C_{e x t}-C_{s c a} \\
& S S A=\omega_{0}=\frac{C_{s c a}}{C_{e x t}}
\end{aligned}
$$

T-matrix codes based on the above described approach were developed for computing the optical properties of aerosols [56], and were used in this work for BB aerosols. The codes were downloaded and installed on the CRAY XC30-ac (athena.ncat.edu) at NCA\&T. For the T-matrix scattering code, the CRAY Compiling Environment (CCE) was used for the FORTRAN codes.

The key input parameters for the calculation of monodispersed particles are the size (radius) of the particles, the wavelength of incident light, and the real and imaginary parts of the refractive index. The optical properties obtained from the T-matrix were averaged over the particles' orientation [35]. The wavelength used for this study was in the range of $500 \mathrm{~nm}$ to $660 \mathrm{~nm}$, in order to compare the calculations with experimentally measured results. Monodispersed particles with diameters of $200 \mathrm{~nm}, 300 \mathrm{~nm}, 400 \mathrm{~nm}$, and $500 \mathrm{~nm}$ were used in the T-matrix calculations to compare with experimental results. The standard deviation for each size selected was also considered to estimate the error due to polydispersity. There was no overlap in the size distributions. For the calculation of polydispersed particles observed in the filter images, we took into account the effective (area-weighted mean radius) radius [57] as the input for calculations that used power law distributions. For log-normal distributions, the geometric mean radius was considered, as well as the square of the log of the geometric standard deviation. Images from filter samples were used to get size and shape information for the T-matrix calculations.

\section{Results and Discussion}

For the initial T-matrix calculations, we considered the BB aerosols obtained from our experiments to have higher concentrations of black carbon. Therefore, we used higher real and imaginary refractive index values following the approach of $\mathrm{Wu}$ et al. [45], which used values obtained from Equations (3) and (4). Experimental average SSA values of BB aerosols from open fire burns and their standard deviations were $0.50 \pm 0.03,0.56 \pm 0.05$, and $0.70 \pm 0.07$, for 300-nm, 400-nm, and 500-nm particles, respectively, and show weak wavelength dependence. The SSA values from the T-matrix calculations of spherical single 300-nm, 400-nm, and 500-nm sized BB particles were 0.43, 0.45, and 0.46, respectively. These are shown in Figures $2-4$. These values show very little wavelength dependence, which was similar to the observations. Similar disagreements between the T-matrix calculations and experiments were observed in soot produced by burning ethylene [58] and propane [46]. All of the modeled SSA values were less than the experimental values for lacey soot, fresh soot particles, $(\sim 41 \%)$, compact soot ( 25\%) [58], and propane soot (56\%). As such, the prescribed RI values for these types of particles were a poor match for the re-aerosolized BB particles examined in this work, suggesting they were chemically and/or morphologically dissimilar. 


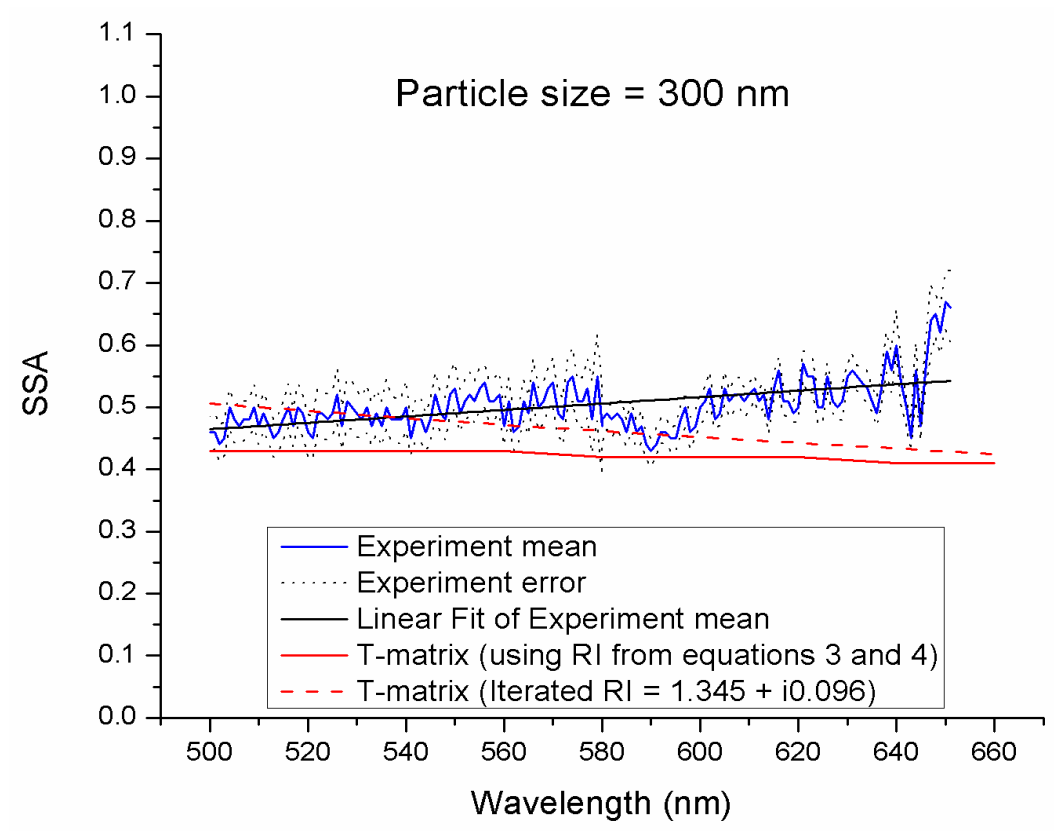

Figure 2. Comparison of experimental single scattering albedo (SSA) values and T-matrix calculated SSA values using the refractive index (RI) following Equations (3) and (4) and using RI = 1.34 + i0.096 to reproduce the experimental values for 300-nm particles collected in distilled water using an impinger.

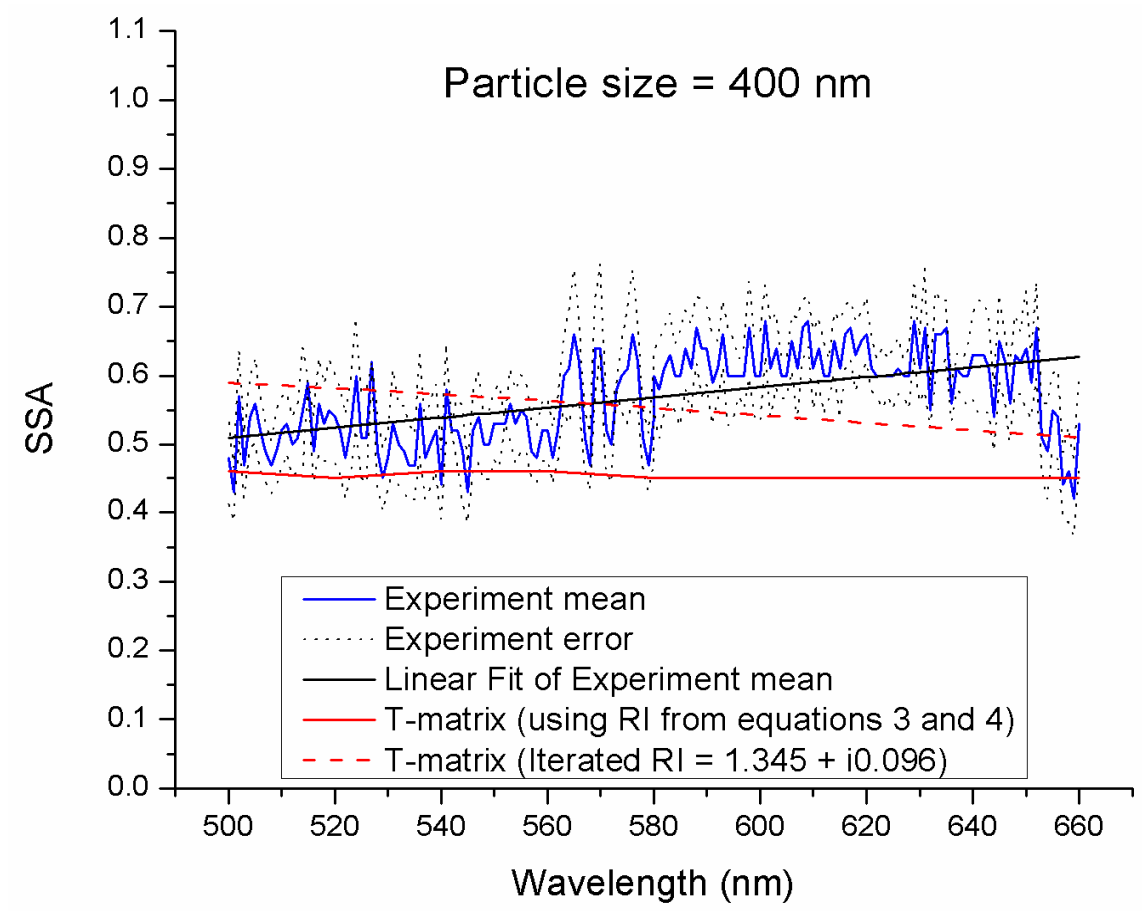

Figure 3. Comparison of experimental SSA values and T-matrix calculated SSA values using RI following Equations ( 3 ) and (4) and using RI = $1.34+\mathrm{i} 0.096$ to reproduce the experimental values for 400-nm particles collected in distilled water using an impinger. 


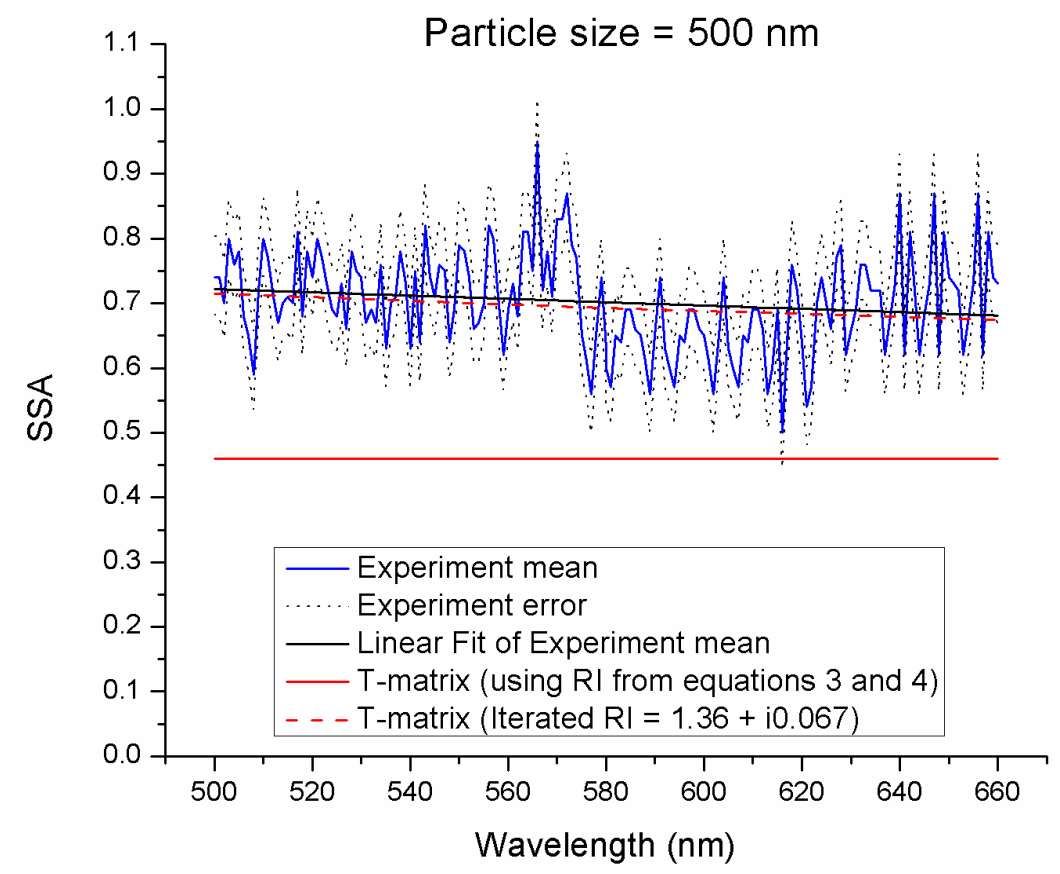

Figure 4. Comparison of experimental SSA values and T-matrix calculated SSA values using RI following Equations ( 3 ) and (4) and using RI $=1.365+\mathrm{i} 0.067$ to reproduce the experimental values for 500-nm particles collected in distilled water using an impinger.

The refractive indices were iteratively varied to reproduce the experimental extinction, scattering cross-sections, and SSA values for the open fire samples. The best fit was obtained for a RI of $1.345+\mathrm{i} 0.096$ for 300-nm and 400-nm particles, and a RI of $1.365+\mathrm{i} 0.067$ for 500-nm particles. This is consistent with the findings of Boenko and Imre [59], where they showed that the real part of the refractive index increased, and the imaginary part decreased, with increasing particle size. In these experiments, the particles were collected in an impinger in distilled water and re-aerosolized to measure their optical properties. We had initially assumed and reported that our measurements represented fresh BB aerosols; since the samples were kept in distilled water and not exposed to the environment, we did not expect photochemical changes to take place. The system would be too diluted for secondary organic aerosol (SOA) formation via acid chemistry. However, the particles may have absorbed water that caused hygroscopic mass growth that affected their refractive indices $[17,31,60,61]$, and all of the semi-volatile soluble organics must have already dissolved in water, leaving a compact core with some water coating. It has been shown that most of the BB aerosol material (on average about $50 \%$ ) seemed to be highly refractory organic material soluble in water [51].

For the 300-nm and 400-nm particles, the SSA values that were found using the iterated RI method decreased with increasing wavelength, which was opposite to the trend shown by the linear fit to the experimental values. The $R^{2}$ values for the linear fit were between 0.26 and 0.29 , though $R^{2}$ is a poor fit indicator when there is little or no observed trend. It was not possible to fit the SSA value using a single value of the RI. In fact, two sets of RIs are needed for the two wavelength ranges: 500-580 nm and 580-660 nm, suggesting a wavelength-dependent RI. Clearly, the calculated SSA using wavelength-dependent RI values based on Equations (3) and (4) provided a wavelength-independent SSA. However, the fit for the 500-nm particles was quite reasonable, suggesting the significance of the size dependence on the RI.

As described by Singh et al., in [50], in the experiments, the data in the 580-660 nm range had poorer signal to noise ratio $(\mathrm{S} / \mathrm{N})$ than data in the $500-580 \mathrm{~nm}$ range due to poor mirror reflectivity. The cross-sections also showed a decrease at higher wavelengths for measurements taken several weeks apart (i.e., different wavelength ranges at different times), despite the consistent size distribution. This was also true at overlapping wavelengths, where there was an abrupt discontinuity 
at $580 \mathrm{~nm}$ (the boundary between the two sets of mirrors). For measurements done on the same day, the discontinuity was reduced for most runs. A constant derived from the difference in cross-sections at $580 \mathrm{~nm}$ was either added or subtracted from the cross-sections at $580-660 \mathrm{~nm}$. It is also worth noting that the level of noise was not the same for different particle sizes, which was largely due to number density differences.

When using the refractive index $1.504+\mathrm{i} 0.009$ reported by Mack [48] for longleaf pine burning smoke, the SSA values obtained were significantly higher than the open fire experimental values. The values were $0.946,0.960$, and 0.962 for $300-\mathrm{nm}, 400-\mathrm{nm}$, and 500-nm particles, respectively. These SSA values and associated scattering and extinction cross-sections were much greater than our laboratory-measured results.

Chen et al. have suggested a wide range of SSA values for wood fuels such as dry Ponderosa pine and white pine needles [62]. The SSA values changed from 0.32 to 0.6 as the burning stage changed from flaming to smoldering. They argued that the change is due to the decrease in the black carbon fraction resulting in a decrease in the imaginary part of the refractive index. Hence, a wide range of acceptable complex refractive indices would produce SSA values within this range. Our refractive index of $1.345+\mathrm{i} 0.096$ for $300-\mathrm{nm}$ and $400-\mathrm{nm}$ particles proves to be more consistent, since the experimental SSA values for 300-nm and 400-nm particles lie within their range (0.32-0.6) of SSA values of pine in open fire burning.

On the other hand, during the FLAME I and II measurements, Levin et al. found that combusting various wild land fuels produced BB particles with geometric mean diameters ranging from $200 \mathrm{~nm}$ to $570 \mathrm{~nm}$, and estimated that their effective refractive indices ranged from 1.55 to 1.80 for the real part, and $0.01-0.50$ for the imaginary part. These increased with increasing particle density, which ranged from 1.22-1.92 $\mathrm{g} \cdot \mathrm{cm}^{-3}$ [49]. The refractive indices also depend on the chemical composition of the aerosols. The refractive indices in our work for BB aerosols $(1.345+\mathrm{i} 0.096$ and $1.365+\mathrm{i} 0.067)$ have a lower real part, and an imaginary part that was within the range of refractive indices for different North American fuels compiled in the thesis by Mack [48] and suggested by Levin [49]. The imaginary part of the refractive index for fuel type in Mack's work ranges from 0.009-0.028. This is lower than our results, which range from 0.065-0.096, and suggests that the impinged BB samples were more absorbing in this work [48]. The literature values of imaginary refractive indices of biomass burning aerosols compiled by Mack were even lower than their own measurements. This is possible, because most of the literature values compiled by Mack are for the aged particles, which have higher SSA values than the fresh ones [17]. Reid et al. compiled SSA values of fresh and aged biomass smoke in their review, which shows an average value for fresh smoke to be around 0.8, and aged smoke to exceed 0.9 [63]. Furthermore, a study by Dubovik et al. has shown that SSA values vary significantly with the source and age of the BB aerosols, and that SSA values correlate with the fraction of black carbon [64].

He et al. $[65,66]$ showed that the two methods they used (Geometric-optics surface waves (GOS) and T-matrix) capture the measured optical properties, but with a $5-20 \%$ difference, and the highest difference being the calculations based on T-matrix. They attributed the discrepancy to the morphology, i.e., the greater dependence on the fractal dimension than on the size of the primary spherules. While our results are consistent with their results that the T-matrix calculations underestimated the SSA values, the discrepancy is even larger if we use the refractive index of $1.95+0.79 \mathrm{i}$ used by He et al. [65,66], which was suggested by Bond et al. [2] for soot produced from the combustion of hydrocarbons and diesel. In fact, we have seen that the refractive index suggested by Bond, when used for biomass burning aerosols, further underestimated the SSA values. One could, therefore, argue that the discrepancy was dominated by fractal dimensions or by the choice of the refractive index. Answering this is beyond the scope the current work, though it is something worth exploring.

An accurate estimate of the $\mathrm{BC}$ radiative effects requires the incorporation of the aging process and coating structure [65,66] and consideration of particle mass [67]. This current work was focused on freshly emitted biomass burning aerosols. Our lab is currently investigating how aging and chemical changes alter the optical properties of BB aerosols. 
Considering the wide variability in the reported values of optical properties of biomass burning aerosols, we decided to run a different experiment where we measured the optical properties of fresh biomass burning aerosols using the laboratory tube furnace, as described in the experimental section. Measurements of optical properties of pinewood were done for particle mobility diameters of $200 \mathrm{~nm}, 300 \mathrm{~nm}$, and $400 \mathrm{~nm}$. Figures 5-7 show the experimental results, the T-matrix calculations of SSA, and the refractive indices used to reproduce the experimental results. For 200-nm, 300-nm, and 400-nm particles, differences in the experimental average SSA and T-matrix modeled average SSA values for the wavelength range $(510-560 \mathrm{~nm})$ were $1 \%, 2 \%$, and $5 \%$, respectively. The T-matrix results were not only compared with the measured SSA values, but also with the extinction and scattering cross-sections, as shown in Figures 8-10, to ensure that the determined refractive indices used accurately reproduced all of the measured optical properties.

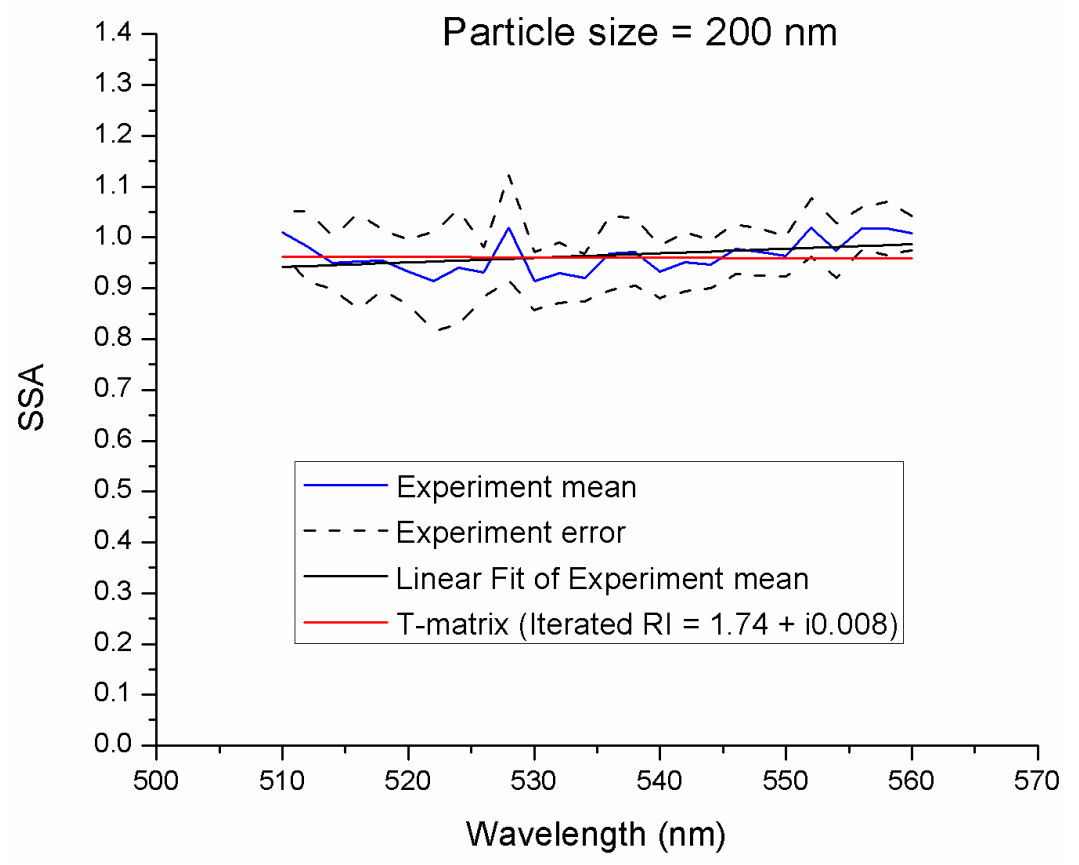

Figure 5. Comparison of T-matrix SSA (using RI = 1.74 + i0.0081) with experimental SSA for 200-nm fresh biomass burning (BB) particles produced using a tube furnace. 


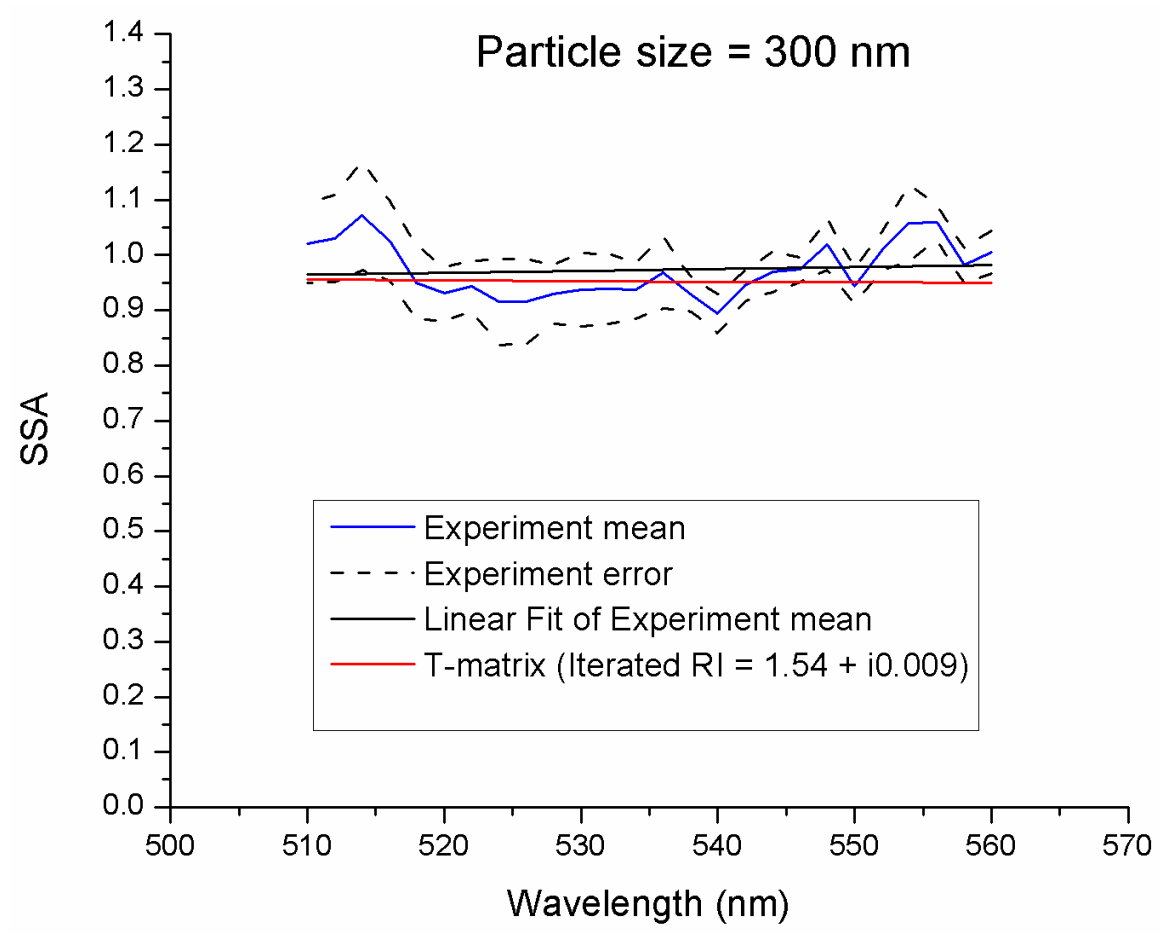

Figure 6. Comparison of T-matrix SSA (RI = $1.54+\mathrm{i} 0.009)$ with experimental SSA for 300-nm fresh BB particles produced using a tube furnace.

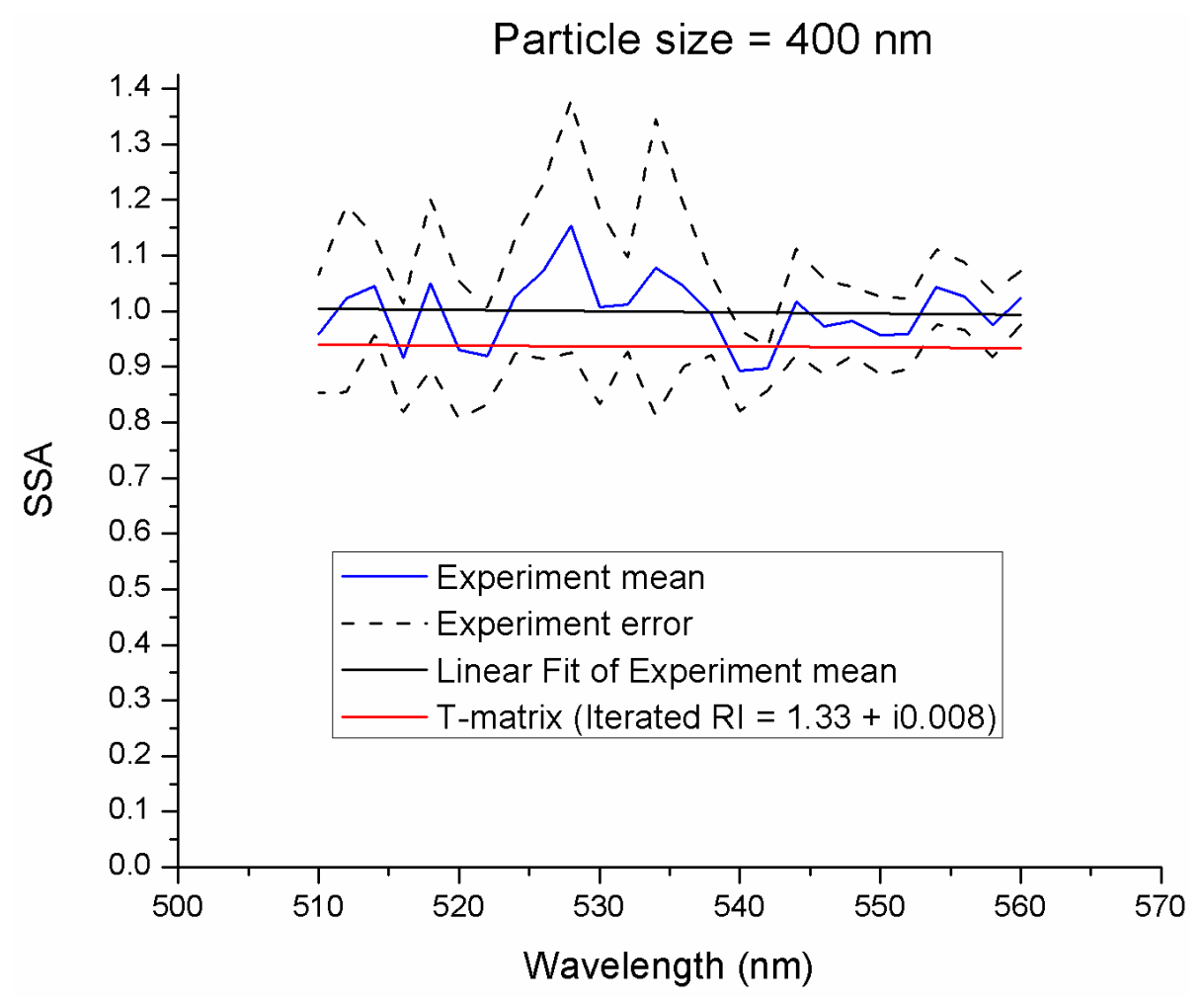

Figure 7. Comparison of T-matrix SSA using $(R I=1.33+\mathrm{i} 0.008)$ with experimental SSA for 400-nm fresh $\mathrm{BB}$ particles produced using a tube furnace. 


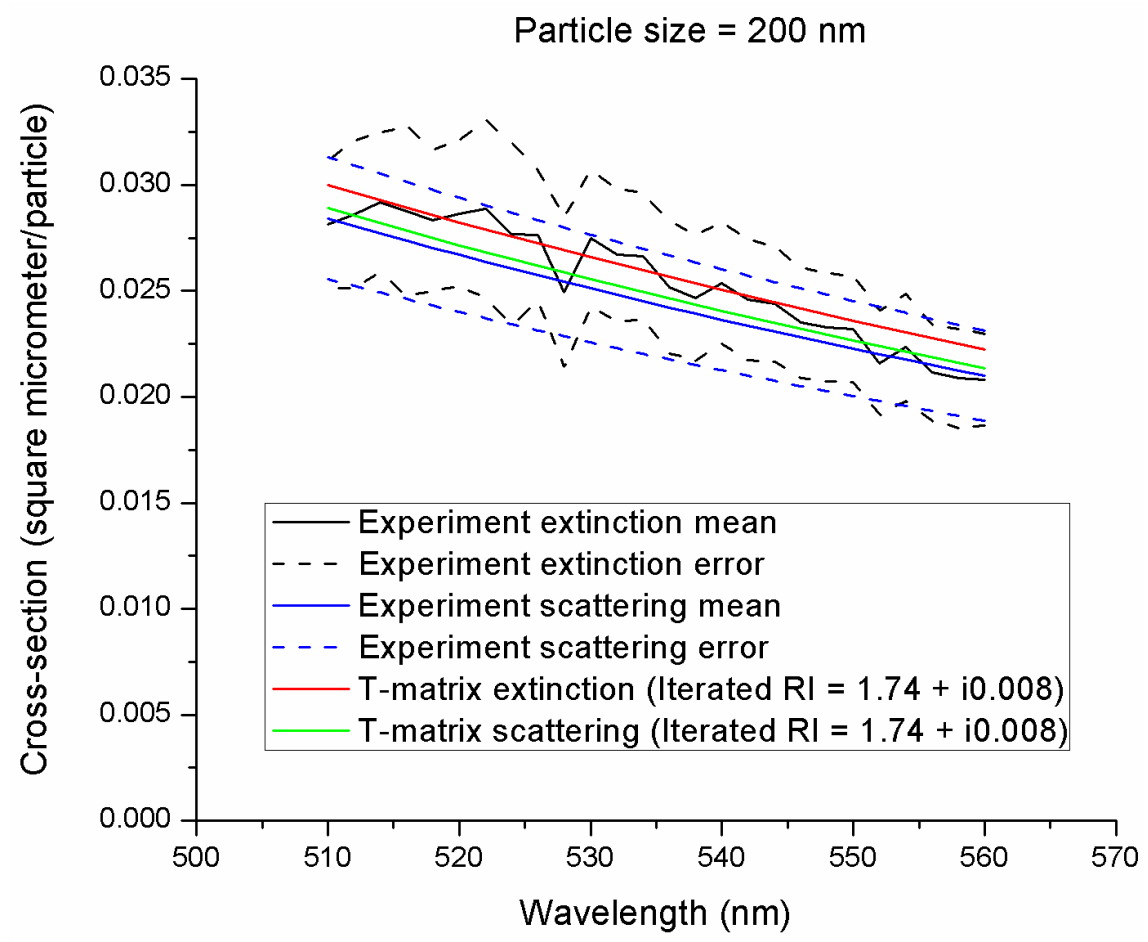

Figure 8. Experimental and calculated values of the extinction and scattering cross-sections for 200-nm particles.

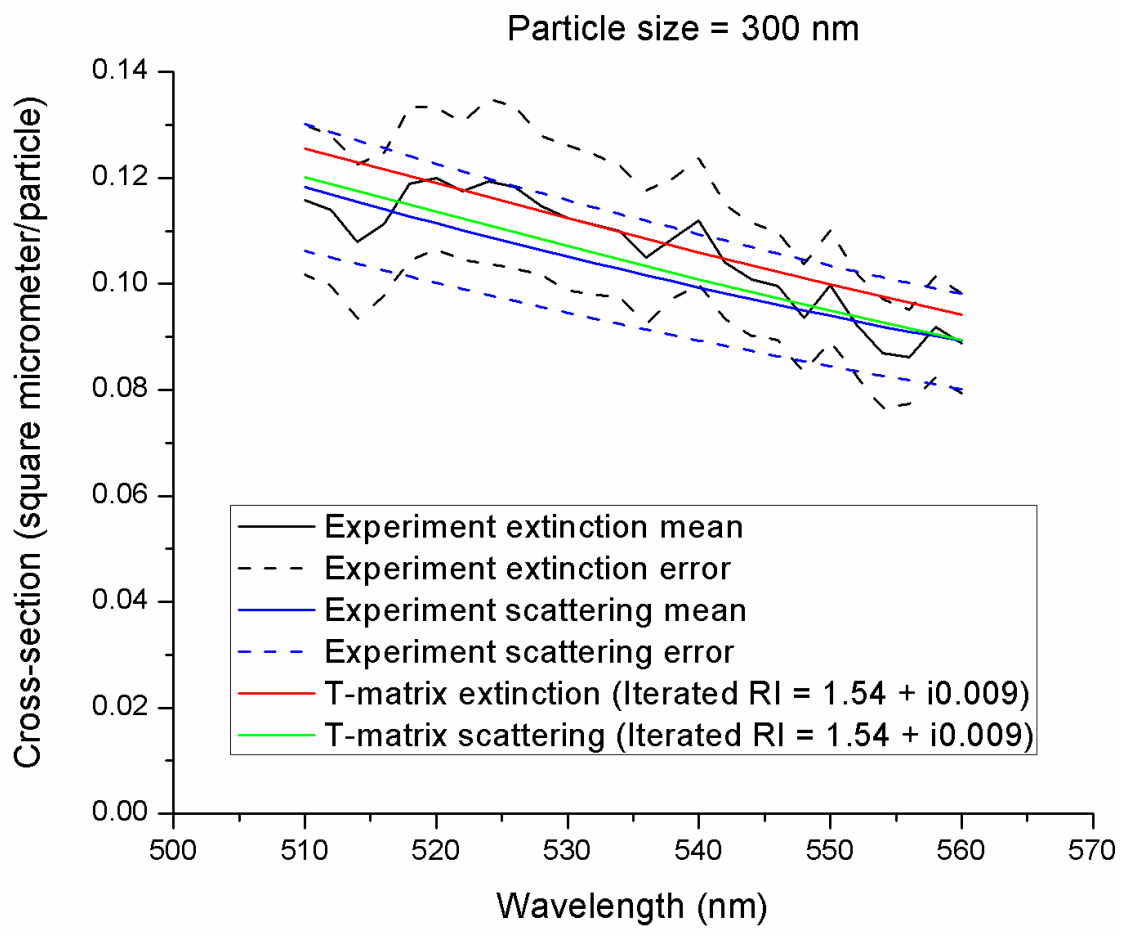

Figure 9. Experimental and calculated values of the extinction and scattering cross-sections for 300-nm particles. 


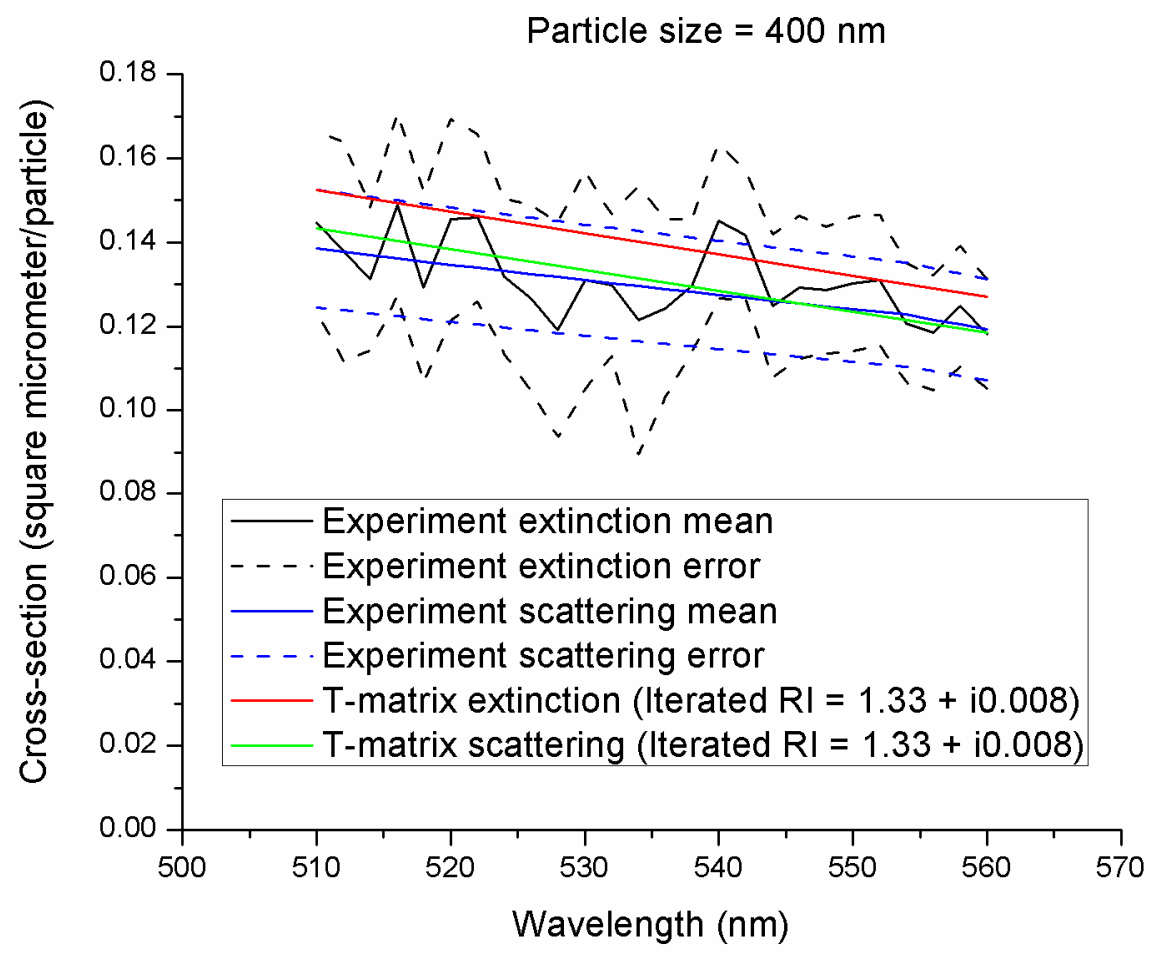

Figure 10. Experimental and calculated values of the extinction and scattering cross-sections for 400-nm particles.

The tube furnace results are not consistent with the earlier findings of Benko [59]. The real part of the RI decreased with increasing particle size. However, the imaginary part showed a very slight decrease with increasing particle size. In all cases, a RI that is independent of the wavelength was sufficient to represent SSA values over the range of wavelengths from $510-560 \mathrm{~nm}$. The real part of the RI ranges from 1.33-1.74, while the imaginary portion hardly changes (i0.008-i0.009). Two of these real RI values are higher than the effective refractive index of 1.41 at $\lambda=565 \mathrm{~nm}$ that was previously determined for fresh smoke [68]; only one was in the range of the real refractive index obtained by McMeeking [69,70] (1.56-1.59). All were slightly lower than other literature values of the imaginary part, which ranged from 0.0093-0.1 [64,71]. However, our values lie within the range of FLAME I and II observations. For particle diameters ranging from $200 \mathrm{~nm}$ to $570 \mathrm{~nm}$, the RI was estimated to range from 1.55 to 1.80 for the real part, and $0.01-0.50$ for the imaginary part, which increased with increasing density of the particles [49].

While the SSA values seem to be constant and independent of the wavelength of light, the extinction and scattering cross-sections show wavelength dependence. Both quantities decrease with increasing wavelengths of light. In the calculations, the refractive indices were adjusted to reproduce the experimental values of extinction and scattering cross-sections. Reproducing the SSA alone will not lead to the correct refractive index.

We analyzed the monomer diameter size distributions, specifically the uncertainty while sampling from the chamber and impinger, to see the impact of polydispersity on the calculated cross-sections that assumed monodispersity. The uncertainty for both the impinger samples and chamber samples were nearly the same, and there was no size overlap between the selected sizes. When polydispersity was considered, the standard deviation in SSA values for impinger samples was about $6 \%$ for the 300-nm particles and 5\% for the 400-nm particles. For the chamber samples, the standard deviation was even smaller, and it was less than $1 \%$ for all sizes.

The scanning electron microscope images of the BB filter samples obtained from the open fire and tube furnace burning of pine are shown in Figures 11 and 12, respectively. The images from filter samples were used to extract information for the T-matrix calculation. For each image used for 
the calculation, pixel resolution $=1024$ (height) $\times 768$ (width) and bits per pixel (or bit depth) $=8$. Image magnification can be up to 10 nanometers (50 times less resolution than a TEM). The shapes of the particles were prolate spheroids. The lengths of the semi-major axis and semi-minor axis were measured using software ImageJ. Up to 5-10 images were taken, and the volume equivalent radius was calculated from $r_{e v}=\sqrt[3]{a^{2} b}$, where $a$ is the horizontal axis, and $b$ is the vertical axis (axis of rotation) of the prolate spheroid. The minimum volume equivalent radius was $53.6 \mathrm{~nm} \pm 10.9$, and the maximum volume equivalent radius was $105.49 \mathrm{~nm} \pm 10.9$ for filter samples from the indoor tube furnace. For the open fire burn, the maximum was $412 \pm 81 \mathrm{~nm}$, and the minimum was $126 \mathrm{~nm} \pm 81$. The aspect ratio used for the calculation was 0.7 , which was the same for both the log-normal and the power-law distributions. The geometric mean of the obtained equivalent radii was then calculated. For the log-normal distribution, the geometric mean diameter was $68.3 \mathrm{~nm}$, and the square of $\log$ of the geometric standard deviation (one of the input parameters for the calculation) was 0.048 . For the power-law distribution, a minimum radius of $53.5 \mathrm{~nm}$ and a maximum radius of $105.49 \mathrm{~nm}$ were used for the calculation. Tables 1 and 2 provide the input data derived from different images both for the open fire and tube furnace burns.

The effective radius of polydisperse particles collected during the open fire was approximately $245 \mathrm{~nm}$, whereas the effective radius for the tube furnace burn was around $76 \mathrm{~nm}$. The effective radius was obtained from the volume equivalent radii for the power-law (Equation (14)) and the log-normal (Equation (15)) distributions.

$$
\begin{gathered}
r_{\text {eff }}=\frac{\left(\mathrm{r}_{2}-r_{1}\right)}{\ln \left(\frac{\mathrm{r}_{2}}{\mathrm{r}_{1}}\right)} \\
\mathrm{r}_{\text {eff }}=\mathrm{r}_{\mathrm{g}} \exp \left(\frac{5 \sigma_{\mathrm{g}}{ }^{2}}{2}\right)
\end{gathered}
$$

Here, $r_{1}$ and $r_{2}$ are the minimum and maximum radii of the size distribution, and $r_{g}$ and $\sigma_{g}$ are the geometric mean and variance of the radii of the size distribution.

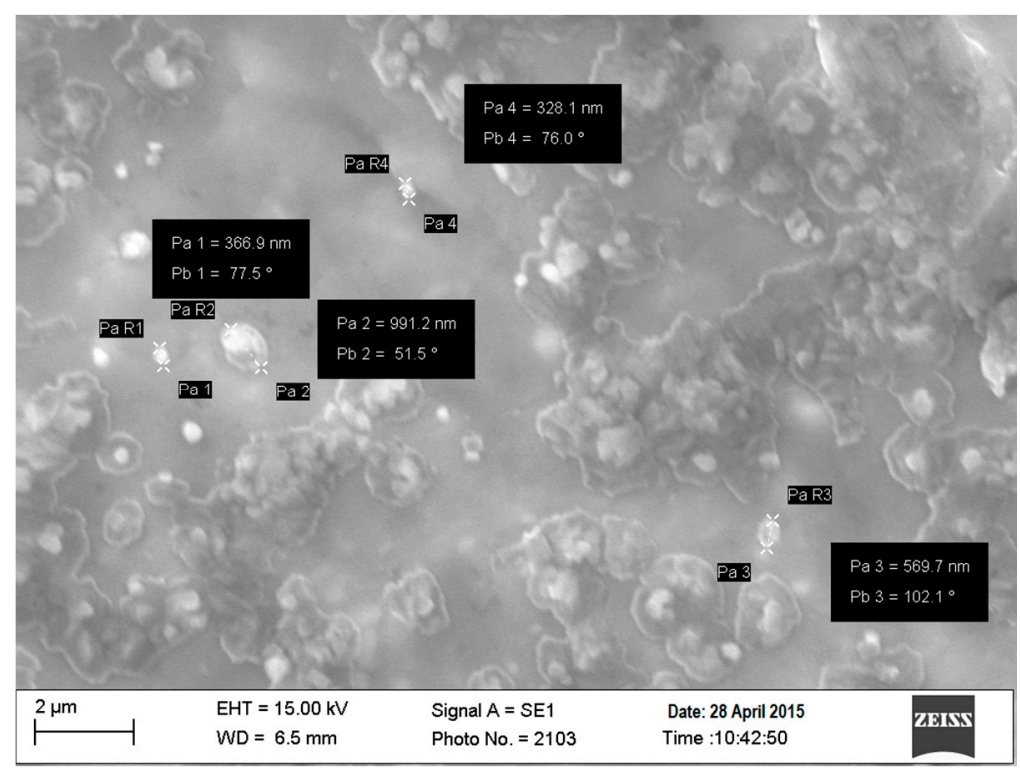

Figure 11. A SEM image of BB aerosol from the smoldering stage of white pine combustion during open fire burn. 


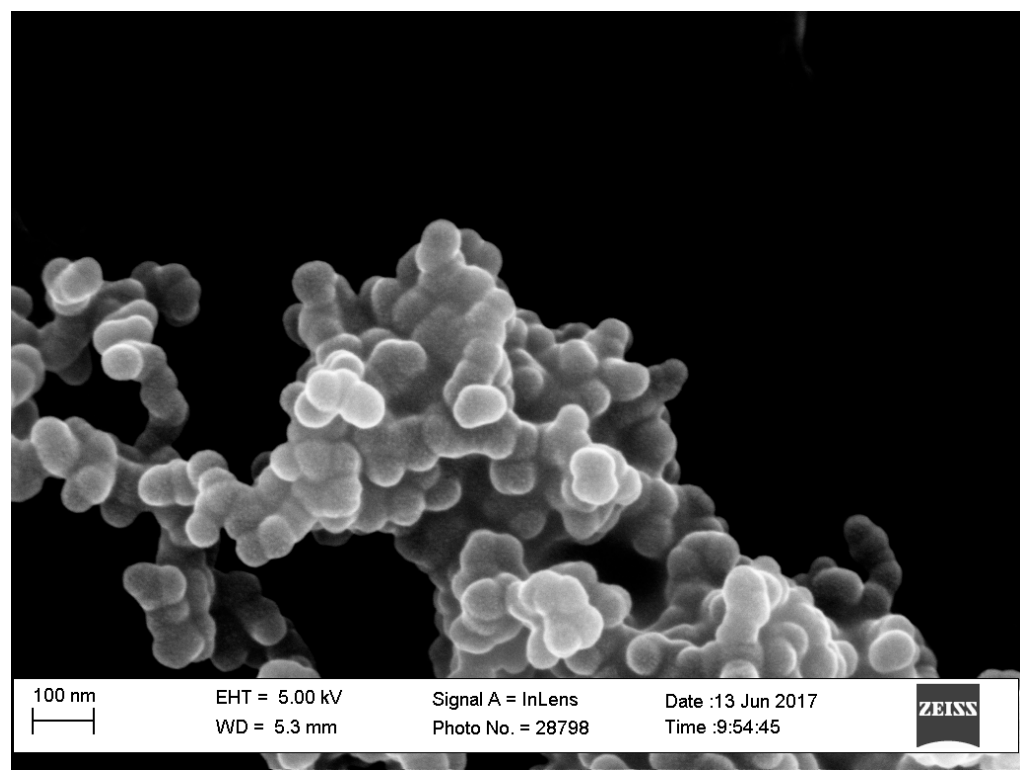

Figure 12. A SEM image of BB aerosol from white pine combustion in the furnace.

Table 1. Input data from images of filter samples from tube furnace.

\begin{tabular}{ccccc}
\hline Sample Number & Vertical Axes $(\mathbf{b} \boldsymbol{\mu m})$ & Horizontal Axes $(\mathbf{a} \boldsymbol{\mu m})$ & Volume Equivalent Radius $\left(\mathbf{r}_{\mathbf{i}} \boldsymbol{\mu m}\right)$ & Aspect Ratio $(\mathbf{a} / \mathbf{b})$ \\
\hline 1 & 0.0847 & 0.0521 & 0.0613 & 0.615 \\
2 & 0.0706 & 0.0467 & 0.0536 & 0.661 \\
3 & 0.0858 & 0.0559 & 0.0645 & 0.652 \\
4 & 0.1080 & 0.0706 & 0.0813 & 0.654 \\
5 & 0.0839 & 0.0571 & 0.0649 & 0.681 \\
6 & 0.1080 & 0.0816 & 0.0896 & 0.756 \\
7 & 0.1160 & 0.1006 & 0.1055 & 0.867 \\
8 & 0.0757 & 0.0563 & 0.0607 & 0.744 \\
9 & 0.0730 & 0.0554 & 0.0556 & 0.759 \\
10 & 0.0678 & 0.0503 & & 0.742 \\
\hline
\end{tabular}

Table 2. Input data from images of filter samples from open fire.

\begin{tabular}{ccccc}
\hline Sample Number & Vertical Axes $(\mathbf{b} \boldsymbol{\mu m})$ & Horizontal Axes $(\mathbf{a} \boldsymbol{\mu m})$ & Volume Equivalent Radius $\left(\mathbf{r}_{\mathbf{i}} \boldsymbol{\mu m}\right)$ & Aspect Ratio $(\mathbf{a} / \mathbf{b})$ \\
\hline 1 & 0.111 & 0.134 & 0.131 & 0.606 \\
2 & 0.365 & 0.525 & 0.412 & 0.747 \\
3 & 0.222 & 0.284 & 0.241 & 0.781 \\
4 & 0.111 & 0.164 & 0.126 & 0.676 \\
5 & 0.185 & 0.259 & 0.207 & 0.714 \\
6 & 0.222 & 0.333 & 0.254 & 0.666 \\
7 & 0.148 & 0.222 & 0.169 & 0.666 \\
8 & 0.148 & 0.240 & 0.173 & 0.614 \\
9 & 0.148 & 0.203 & 0.164 & 0.729 \\
10 & 0.111 & 0.166 & 0.126 & 0.660 \\
\hline
\end{tabular}

The filter samples for both the open fire and the indoor tube furnace burn were collected in the same manner, and the images were taken soon after the filter samples were collected. It is fair to assume that they both represent fresh BB samples. For the T-matrix calculations using the images, the power-law and log-normal distributions were used. To reproduce the SSA value of 0.958 for fresh BB in the laboratory, a RI of $1.88+\mathrm{i} 0.008$ was determined. The SSA values remained the same for log-normal as well as power-law size distributions, and for both open fire and tube furnace samples. When taking into account the size distribution, the real part of the RI increased compared with the results based on spheres. The small number of images used (5-10), and the limited resolution of SEM used here compared with transmission electron microscopy (TEM) can also contribute to the uncertainty in determining the volume equivalent radius of the filter samples. The assumption of the monodisperse mean (or volume-equivalent) diameter of the soot monomer may neglect the effect of 
monomer polydispersity on the optical properties of soot aggregates. Previous studies suggested that performing calculations using a monodisperse diameter may neglect the effect of multiple internal scattering on radiative properties of BB fractal aggregates [72,73]. Studies have shown that the light scattering of fresh BB aggregates were influenced by monomer polydispersity [74].

\section{Conclusions}

The RI is an important parameter in describing the radiative impacts of aerosols. It is important to constrain the RI of aerosol components, since there is still significant uncertainty regarding the RI of biomass burning aerosols. A wide range of values has been reported in the literature, and the trends of the dependence of the RI on size are inconsistent. For example, the imaginary part of the RI for brown carbon at $350 \mathrm{~nm}$ was reported to be 0.0082 [75] and 0.009 at $405 \mathrm{~nm}$ [76]. A recent study, however, measured the $\mathrm{RI}$ of atmospheric $\mathrm{BrC}$, originating from various emission sources and secondary processes, and found the imaginary part of the RI to be four times higher: 0.042 at $365 \mathrm{~nm}$, and 0.037 at $405 \mathrm{~nm}$ [77].

Several factors contribute to the calculated uncertainties. These factors include uncertainties in aerosol species mass concentration, unknown size distributions, the poorly characterized RI of materials, and chemical species making up the aerosols, particle morphology, burning conditions, and the age of the aerosols [78]. We have observed fresh BB aerosols that are more scattering than previous observations, and would be represented by a lower imaginary portion of the RI than previously determined. The main results of this work can be summarized as follows:

The refractive index used for strongly absorbing $\mathrm{BB}$ aerosols produced from the combustion of hydrocarbons and diesel cannot be used for BB aerosols, as these calculations resulted in SSA values smaller than the experimentally measured values. The RI for these types of BB aerosols suggested in the literature should not be used for biomass burning aerosols.

Our results show that the refractive index exhibited wavelength dependence for the impinger samples, and was nearly independent of the wavelength of incident light used for tube furnace samples. This suggests that the RI depends more strongly on the particle size and structure rather than wavelength in the $500-580 \mathrm{~nm}$ region. There is no clear RI trend with burning conditions, as the real part of the refractive index increased with increasing particle size for the open fire burn and decreased with increasing particle size for the tube furnace burn. The imaginary part decreased slightly with increasing particle size. The scattering and extinction cross-sections showed wavelength dependence. Both decreased with increasing wavelength for both experimental and calculated results.

Our results also suggest that using the SSA alone will lead to an error in extracting the refractive index, since one can produce different combinations of the cross-sections from different real and imaginary RI, but produce the same SSA. Therefore, the refractive index should also reproduce all of the cross-sections. Burning conditions can affect the optical properties of biomass burning aerosols, as shown by the different results for outdoor burning and the tube furnace burning of white pine in our work. For BB particles collected in distilled water using an impinger, hygroscopic mass growth must have influenced the refractive index, and hence the extinction, scattering, and SSA values of the aerosol. Furthermore, the wavelength dependence of the RI index suggests a change in the chemical composition and structure while in solution or upon nebulization. Since the fidelity of particles collected with an impinger is quite poor, this method does not represent fresh BB aerosols as we previously claimed, and should not be used to access their optical properties.

We recommend more carefully designed laboratory experiments to measure scattering and absorption cross-sections, and the use of the T-matrix or more robust versions of the T-matrix model such as the Discrete-Dipole Scattering (DDSCAT) method to extract an accurate RI for each sample as a function of size, shape, chemical composition, mass, aging stage, burn stage, and burn conditions. 
Acknowledgments: The authors acknowledge toe financial support provided by the National Science Foundation under grant \# NSF-AGS 1555479 to accomplish this work. We also acknowledge the use of the computational facility obtained through and NSF Grant No. \#1429464. Finally, we acknowledge the support by the Joint School of Nanoscience and Nanoengineering for the use of the Electron Microscopy facility.

Author Contributions: Solomon Bililign and Marc N. Fiddler conceived and designed the experiments; Damon Smith performed the laboratory experiments; Samin Poudel carried out the theoretical calculation and analyzed the data; K.M Flurchick contributed to installing and compiling and testing the T-matrix code Solomon Bililign and Samin Poudel wrote the paper.

Conflicts of Interest: The authors declare no conflict of interest.

\section{References}

1. Bond, T.C.; Doherty, S.J.; Fahey, D.W.; Forster, P.M.; Berntsen, T.; DeAngelo, B.J.; Flanner, M.G.; Ghan, S.; Kärcher, B.; Koch, D.; et al. Bounding the role of black carbon in the climate system: A scientific assessment. J. Geophys. Res. Atmos. 2013, 118, 5380-5552. [CrossRef]

2. Bond, T.C.; Bergstrom, R.W. Light absorption by carbonaceous particles: An investigative review. Aerosol Sci. Technol. 2006, 40, 27-67. [CrossRef]

3. Buseck, P.R.; Adachi, K.; Gelencsér, A.; Tompa, É.; Pósfai, M. Are black carbon and soot the same? Atmos. Chem. Phys. Discuss. 2012, 12, 24821-24846. [CrossRef]

4. Petzold, A.; Ogren, J.A.; Fiebig, M.; Laj, P.; Li, S.M.; Baltensperger, U.; Holzer-Popp, T.; Kinne, S.; Pappalardo, G.; Sugimoto, N.; et al. Recommendations for reporting "black carbon" measurements. Atmos. Chem. Phys. 2013, 13, 8365-8379. [CrossRef]

5. Hansen, J.; Nazarenko, L. Soot climate forcing via snow and ice albedos. Proc. Natl. Acad. Sci. USA 2004, 101, 423-428. [CrossRef] [PubMed]

6. Cairns, B.; Mishchenko, M. The Need for Aerosol and Cloud Measurements from Space: Essential Contributions from a Rapid Reflight of the Aerosol Polarimetry Sensor; NASA Goddard Institute for Space Studies: New York, NY, USA, 2011.

7. Hansen, J.; Sato, M.; Kharecha, P.; Von Schuckmann, K. Earth's energy imbalance and implications. Atmos. Chem. Phys. 2011, 11, 13421-13449. [CrossRef]

8. Kiehl, J.T. Twentieth century climate model response and climate sensitivity. Geophys. Res. Lett. $2007,34$. [CrossRef]

9. Lohmann, U.; Ferrachat, S. Impact of parametric uncertainties on the present-day climate and on the anthropogenic aerosol effect. Atmos. Chem. Phys. 2010, 10, 11373-11383. [CrossRef]

10. Mishchenko, M.I.; Cairns, B.; Hansen, J.E.; Travis, L.D.; Burg, R.; Kaufman, Y.J.; Martins, J.V.; Shettle, E.P. Monitoring of aerosol forcing of climate from space: Analysis of measurement requirements. J. Quant. Spectrosc. Radiat. Transf. 2004, 88, 149-161. [CrossRef]

11. Mishchenko, M.I.; Cairns, B.; Hansen, J.E.; Travis, L.D.; Kopp, G.; Schueler, C.F.; Fafaul, B.A.; Hooker, R.J.; Maring, H.B.; Itchkawich, T. Accurate Monitoring of Terrestrial Aerosols and Total Solar Irradiance: Introducing the Glory Mission. Bull. Am. Meteorol. Soc. 2007, 88, 677-691. [CrossRef]

12. Penner, J.E.; Xu, L.; Wang, M. Satellite methods underestimate indirect climate forcing by aerosols. Proc. Natl. Acad. Sci. USA 2011, 108, 13404-13408. [CrossRef] [PubMed]

13. Schwartz, S.E. Uncertainty requirements in radiative forcing of climate change. J. Air Waste Manag. Assoc. 2004, 54, 1351-1359. [CrossRef] [PubMed]

14. Solomon, S. (Ed.) Climate Change 2007-the Physical Science Basis: Working Group I Contribution to the Fourth Assessment Report of the IPCC; Cambridge University Press: Cambridge, UK; New York, NY, USA, 2007.

15. Stier, P.; Seinfeld, J.H.; Kinne, S.; Boucher, O. Aerosol absorption and radiative forcing. Atmos. Chem. Phys. 2007, 7, 5237-5261. [CrossRef]

16. Loeb, N.G.; Su, W. Direct aerosol radiative forcing uncertainty based on a radiative perturbation analysis. J. Clim. 2010, 23, 5288-5293. [CrossRef]

17. Abel, S.J.; Haywood, J.M.; Highwood, E.J.; Li, J.; Buseck, P.R. Evolution of biomass burning aerosol properties from an agricultural fire in southern Africa. Geophys. Res. Lett. 2003, 30, 1783. [CrossRef] 
18. Lewis, K.; Arnott, W.; Moosmüller, H.; Chakrabarty, R.; Carrico, C.; Kreidenweis, S.; Day, D.; Malm, W.; Laskin, A.; Jimenez, J. Reduction in biomass burning aerosol light absorption upon humidification: Roles of inorganically-induced hygroscopicity, particle collapse, and photoacoustic heat and mass transfer. Atmos. Chem. Phys. 2009, 9, 8949-8966. [CrossRef]

19. Schnaiter, M.; Horvath, H.; Mohler, O.; Naumann, K.H.; Saathoff, H.; Schock, O.W. UV-VIS-NIR spectral optical properties of soot and soot-containing aerosols. J. Aerosol Sci. 2003, 34, 1421-1444. [CrossRef]

20. Zhang, R.; Khalizov, A.F.; Pagels, J.; Zhang, D.; Xue, H.; McMurry, P.H. Variability in morphology, hygroscopicity, and optical properties of soot aerosols during atmospheric processing. Proc. Natl. Acad. Sci. USA 2008, 105, 10291-10296. [CrossRef] [PubMed]

21. Kahnert, F.M. Numerical methods in electromagnetic scattering theory. J. Quant. Spectrosc. Radiat. Transf. 2003, 79, 775-824. [CrossRef]

22. Mishchenko, M.I.; Hovenier, J.W.; Travis, L.D. (Eds.) Light Scattering by Nonspherical Particles: Theory, Measurement, and Applications; Academic Press: San Diego, CA, USA, 2002.

23. Mishchenko, M.I.; Travis, L.D.; Lacis, A.A. (Eds.) Scattering, Absorption, and Emission of Light by Small Particles; Cambridge University Press: Cambridge, UK; New York, NY, USA, 2002.

24. Wriedt, T. Light scattering theory and programs: Discussion of latest advances and open problems. J. Quant. Spectrosc. Radiat. Transf. 2012, 113, 2465-2469. [CrossRef]

25. Berry, M.V.; Percival, I.C. Optics of Fractal Clusters such as Smoke. J. Mod. Opt. 1986, 33, 577-591. [CrossRef]

26. Chen, H.; Iskander, M.; Penner, J. Light scattering and absorption by fractal agglomerates and coagulations of smoke aerosols. J. Mod. Opt. 1990, 37, 171-181. [CrossRef]

27. Khlebtsov, N.G. Optics of Fractal Clusters in the Anomalous Diffraction Approximation. J. Mod. Opt. 1993, 40, 2221-2235. [CrossRef]

28. Mountain, R.D.; Mulholland, G. Light scattering from simulated smoke agglomerates. Langmuir 1988, 4, 1321-1326. [CrossRef]

29. Singham, S.B.; Bohren, C.F. Scattering of unpolarized and polarized light by particle aggregates of different size and fractal dimension. Langmuir 1993, 9, 1431-1435. [CrossRef]

30. Fuller, K.A. Scattering and absorption cross sections of compounded spheres. III. Spheres containing arbitrarily located spherical inhomogeneities. J. Opt. Soc. Am. A 1995, 12, 893-904. [CrossRef]

31. Fuller, K.A.; Malm, W.C.; Kreidenweis, S.M. Effects of mixing on extinction by carbonaceous particles. J. Geophys. Res. Atmos. 1999, 104, 15941-15954. [CrossRef]

32. Liu, L.; Mishchenko, M.I. Effects of aggregation on scattering and radiative properties of soot aerosols. J. Geophys. Res. Atmos. 2005, 110, D11211. [CrossRef]

33. Mackowski, D.W. Calculation of total cross sections of multiple-sphere clusters. J. Opt. Soc. Am. A 1994, 11, 2851-2861. [CrossRef]

34. Mishchenko, M.I. Electromagnetic scattering by nonspherical particles: A tutorial review. J. Quant. Spectrosc. Radiat. Transf. 2009, 110, 808-832. [CrossRef]

35. Mishchenko, M.I.; Travis, L.D.; Mackowski, D.W. T-matrix computations of light scattering by nonspherical particles: A review. J. Quant. Spectrosc. Radiat. Transf. 1996, 55, 535-575. [CrossRef]

36. Mishchenko, M.I.; Videen, G.; Khlebtsov, N.G.; Wriedt, T. Comprehensive T-matrix reference database: A 2012-2013 update. J. Quant. Spectrosc. Radiat. Transf. 2013, 123, 145-152. [CrossRef]

37. Mishchenko, M.I.; Videen, G.; Khlebtsov, N.G.; Wriedt, T.; Zakharova, N.T. Comprehensive T-matrix reference database: A 2006-07 update. J. Quant. Spectrosc. Radiat. Transf. 2008, 109, 1447-1460. [CrossRef]

38. Mackowski, D. A general superposition solution for electromagnetic scattering by multiple spherical domains of optically active media. J. Quant. Spectrosc. Radiat. Transf. 2014, 133, 264-270. [CrossRef]

39. Wu, T.; Coeur-Tourneur, C.; Dhont, G.; Cassez, A.; Fertein, E.; He, X.; Chen, W. Simultaneous monitoring of temporal profiles of $\mathrm{NO}_{3}, \mathrm{NO}_{2}$ and $\mathrm{O}_{3}$ by incoherent broadband cavity enhanced absorption spectroscopy for atmospheric applications. J. Quant. Spectrosc. Radiat. Transf. 2014, 133, 199-205. [CrossRef]

40. Liu, L.; Mishchenko, M.I.; Arnott, W.P. A study of radiative properties of fractal soot aggregates using the superposition T-matrix method. J. Quant. Spectrosc. Radiat. Transf. 2008, 109, 2656-2663. [CrossRef]

41. Sorensen, C. Light scattering by fractal aggregates: A review. Aerosol Sci. Technol. 2001, 35, 648-687. [CrossRef]

42. Dastanpour, R.; Rogak, S.N. The effect of primary particle polydispersity on the morphology and mobility diameter of the fractal agglomerates in different flow regimes. J. Aerosol Sci. 2016, 94, 22-32. [CrossRef] 
43. Liu, L.; Mishchenko, M.I. Scattering and radiative properties of complex soot and soot-containing aggregate particles. J. Quant. Spectrosc. Radiat. Transf. 2007, 106, 262-273. [CrossRef]

44. Chakrabarty, R.K.; Beres, N.D.; Moosmüller, H.; China, S.; Mazzoleni, C.; Dubey, M.K.; Liu, L.; Mishchenko, M.I. Soot superaggregates from flaming wildfires and their direct radiative forcing. Sci. Rep. 2014, 4, 5508. [CrossRef] [PubMed]

45. Wu, Y.; Cheng, T.; Zheng, L.; Chen, H. Effect of morphology on the optical properties of soot aggregated with spheroidal monomers. J. Quant. Spectrosc. Radiat. Transf. 2016, 168, 158-169. [CrossRef]

46. Kim, J.; Bauer, H.; Dobovičnik, T.; Hitzenberger, R.; Lottin, D.; Ferry, D.; Petzold, A. Assessing Optical Properties and Refractive Index of Combustion Aerosol Particles Through Combined Experimental and Modeling Studies. Aerosol Sci. Technol. 2015, 49, 340-350. [CrossRef]

47. Abo Riziq, A.; Erlick, C.; Dinar, E.; Rudich, Y. Optical properties of absorbing and non-absorbing aerosols retrieved by cavity ring down (CRD) spectroscopy. Atmos. Chem. Phys. 2007, 7, 1523-1536. [CrossRef]

48. Mack, L.E. Cavity Ring-Down Spectroscopy and the Retrieval of Aerosol Optical Properties from Biomass Burning During Flame 2. Master's Thesis, Colorado State University, Colorado, CO, USA, 2008.

49. Levin, E.J.T.; McMeeking, G.R.; Carrico, C.M.; Mack, L.E.; Kreidenweis, S.M.; Wold, C.E.; Moosmüller, H.; Arnott, W.P.; Hao, W.M.; Collett, J.L.; et al. Biomass burning smoke aerosol properties measured during Fire Laboratory at Missoula Experiments (FLAME). J. Geophys. Res. Atmos. 2010, 115, D18210. [CrossRef]

50. Singh, S.; Fiddler, M.N.; Bililign, S. Measurement of size-dependent single scattering albedo of fresh biomass burning aerosols using the extinction-minus-scattering technique with a combination of cavity ring-down spectroscopy and nephelometry. Atmos. Chem. Phys. 2016, 16, 13491-13507. [CrossRef]

51. Mayol-Bracero, O.L.; Guyon, P.; Graham, B.; Roberts, G.; Andreae, M.O.; Decesari, S.; Facchini, M.C.; Fuzzi, S.; Artaxo, P. Water-soluble organic compounds in biomass burning aerosols over Amazonia 2. Apportionment of the chemical composition and importance of the polyacidic fraction. J. Geophys. Res. Atmos. 2002, 107, 8091. [CrossRef]

52. Trump, E.R.; Epstein, S.A.; Riipinen, I.; Donahue, N.M. Wall effects in smog chamber experiments: A model study. Aerosol Sci. Technol. 2016, 50, 1180-1200. [CrossRef]

53. Singh, S.; Fiddler, M.N.; Smith, D.; Bililign, S. Error Analysis and Uncertainty in the Determination of Aerosol Optical Properties Using Cavity Ring-Down Spectroscopy, Integrating Nephelometry, and the Extinction-Minus-Scattering Method. Aerosol Sci. Technol. 2014, 48, 1345-1359. [CrossRef]

54. Waterman, P.C. Matrix formulation of electromagnetic scattering. Proc. IEEE 1965, 53, 805-812. [CrossRef]

55. Mishchenko, M.I.; Travis, L.D. Capabilities and limitations of a current FORTRAN implementation of the T-matrix method for randomly oriented, rotationally symmetric scatterers. J. Quant. Spectrosc. Radiat. Transf. 1998, 60, 309-324. [CrossRef]

56. Mischenko, N.; Travis, L.D.; Mackowski, D.W. T-Matrix Codes for Computing Electromagnetic Scattering by Nonspherical and Aggregated Particles. Available online: https://www.giss.nasa.gov/staff/mmishchenko/ t_matrix.html (accessed on 15 June 2016).

57. Grainger, R.G. Some Useful Formulae for Aerosol Size Distributions and Optical Properties. 2015. Available online: http:/ / eodg.atm.ox.ac.uk/user/grainger/research/aerosols.pdf (accessed on 1 December 2016).

58. Radney, J.G.; You, R.; Ma, X.; Conny, J.M.; Zachariah, M.R.; Hodges, J.T.; Zangmeister, C.D. Dependence of Soot Optical Properties on Particle Morphology: Measurements and Model Comparisons. Environ. Sci. Technol. 2014, 48, 3169-3176. [CrossRef] [PubMed]

59. Benko, D.; Molnar, A.; Imre, K. Study on the size dependence of complex refractive index of atmospheric aerosol particles over Central Europe. Idõjárás 2009, 113, 157-175.

60. Mikhailov, E.F.; Vlasenko, S.S.; Podgorny, I.A.; Ramanathan, V.; Corrigan, C.E. Optical properties of soot-water drop agglomerates: An experimental study. J. Geophys. Res. Atmos. 2006, 111, D07209. [CrossRef]

61. Moffet, R.C.; Prather, K.A. In-situ measurements of the mixing state and optical properties of soot with implications for radiative forcing estimates. Proc. Natl. Acad. Sci. USA 2009, 106, 11872-11877. [CrossRef] [PubMed]

62. Chen, L.W.A.; Moosmüller, H.; Arnott, W.P.; Chow, J.C.; Watson, J.G.; Susott, R.A.; Babbitt, R.E.; Wold, C.E.; Lincoln, E.N.; Hao, W.M. Particle emissions from laboratory combustion of wildland fuels: In situ optical and mass measurements. Geophys. Res. Lett. 2006, 33, L04803. [CrossRef] 
63. Reid, J.S.; Eck, T.F.; Christopher, S.A.; Koppmann, R.; Dubovik, O.; Eleuterio, D.; Holben, B.N.; Reid, E.A.; Zhang, J. A review of biomass burning emissions part III: Intensive optical properties of biomass burning particles. Atmos. Chem. Phys. 2005, 5, 827-849. [CrossRef]

64. Dubovik, O.; Holben, B.; Eck, T.F.; Smirnov, A.; Kaufman, Y.J.; King, M.D.; Tanré, D.; Slutsker, I. Variability of absorption and optical properties of key aerosol types observed in worldwide locations. J. Atmos. Sci. 2002, 59, 590-608. [CrossRef]

65. He, C.; Takano, Y.; Liou, K.N.; Yang, P.; Li, Q.; Mackowski, D.W. Intercomparison of the GOS approach, superposition T-matrix method, and laboratory measurements for black carbon optical properties during aging. J. Quant. Spectrosc. Radiat. Transf. 2016, 184, 287-296. [CrossRef]

66. He, C.; Liou, K.N.; Takano, Y.; Zhang, R.; Levy Zamora, M.; Yang, P.; Li, Q.; Leung, L.R. Variation of the radiative properties during black carbon aging: Theoretical and experimental intercomparison. Atmos. Chem. Phys. 2015, 15, 11967-11980. [CrossRef]

67. Dastanpour, R.; Momenimovahed, A.; Thomson, K.; Olfert, J.; Rogak, S. Variation of the optical properties of soot as a function of particle mass. Carbon 2017, 124, 201-211. [CrossRef]

68. Guyon, P.; Graham, B.; Roberts, G.C.; Mayol-Bracero, O.L.; Maenhaut, W.; Artaxo, P.; Andreae, M.O. In-canopy gradients, composition, sources, and optical properties of aerosol over the Amazon forest. J. Geophys. Res. Atmos. 2003, 108, 4591. [CrossRef]

69. McMeeking, G.R.; Kreidenweis, S.M.; Carrico, C.M.; Collett, J.L.; Day, D.E.; Malm, W.C. Observations of smoke-influenced aerosol during the Yosemite Aerosol Characterization Study: 2. Aerosol scattering and absorbing properties. J. Geophys. Res. Atmos. 2005, 110, D18209. [CrossRef]

70. McMeeking, G.R.; Kreidenweis, S.M.; Carrico, C.M.; Lee, T.; Collett, J.L.; Malm, W.C. Observations of smoke-influenced aerosol during the Yosemite Aerosol Characterization Study: Size distributions and chemical composition. J. Geophys. Res. Atmos. 2005, 110, D09206. [CrossRef]

71. Carrico, C.M.; Kreidenweis, S.M.; Malm, W.C.; Day, D.E.; Lee, T.; Carrillo, J.; McMeeking, G.R.; Collett, J.L. Hygroscopic growth behavior of a carbon-dominated aerosol in Yosemite National Park. Atmos. Environ. 2005, 39, 1393-1404. [CrossRef]

72. Yon, J.; Liu, F.; Bescond, A.; Caumont-Prim, C.; Rozé, C.; Ouf, F.X.; Coppalle, A. Effects of multiple scattering on radiative properties of soot fractal aggregates. J. Quant. Spectrosc. Radiat. Transf. 2014, 133, 374-381. [CrossRef]

73. Liu, F.; Wong, C.; Snelling, D.R.; Smallwood, G.J. Investigation of absorption and scattering properties of soot aggregates of different fractal dimension at $532 \mathrm{~nm}$ using RDG and GMM. Aerosol Sci. Technol. 2013, 47, 1393-1405. [CrossRef]

74. Wu, Y.; Cheng, T.; Zheng, L.; Chen, H. A study of optical properties of soot aggregates composed of poly-disperse monomers using the superposition T-matrix method. Aerosol Sci. Technol. 2015, 49, 941-949. [CrossRef]

75. Lack, D.A.; Langridge, J.M.; Bahreini, R.; Cappa, C.D.; Middlebrook, A.M.; Schwarz, J.P. Brown carbon and internal mixing in biomass burning particles. Proc. Natl. Acad. Sci. USA 2012, 109, 14802-14807. [CrossRef] [PubMed]

76. Liu, J.; Bergin, M.; Guo, H.; King, L.; Kotra, N.; Edgerton, E.; Weber, R. Size-resolved measurements of brown carbon in water and methanol extracts and estimates of their contribution to ambient fine-particle light absorption. Atmos. Chem. Phys. 2013, 13, 12389-12404. [CrossRef]

77. Shamjad, P.M.; Tripathi, S.N.; Thamban, N.M.; Vreeland, H. Refractive Index and Absorption Attribution of Highly Absorbing Brown Carbon Aerosols from an Urban Indian City-Kanpur. Sci. Rep. 2016, 6, 37735. [CrossRef] [PubMed]

78. Cai, Y.; Montague, D.C.; Deshler, T. Comparison of measured and calculated scattering from surface aerosols with an average, a size-dependent, and a time-dependent refractive index. J. Geophys. Res. Atmos. 2011, 116. [CrossRef]

(C) 2017 by the authors. Licensee MDPI, Basel, Switzerland. This article is an open access article distributed under the terms and conditions of the Creative Commons Attribution (CC BY) license (http:// creativecommons.org/licenses/by/4.0/). 